Article

\title{
Intramolecular Spin State Locking in Iron(II) 2,6-Di(pyrazol-3-yl)pyridine Complexes by Phenyl Groups: An Experimental Study
}

\author{
Yulia Nelyubina ${ }^{1,2, *}$, Alexander Polezhaev ${ }^{1,3}$, Alexander Pavlov ${ }^{1}$, Dmitrii Aleshin ${ }^{1,4}$, \\ Svetlana Savkina ${ }^{1}$, Nikolay Efimov ${ }^{2}$ (D) , Teimur Aliev ${ }^{1}$ and Valentin Novikov ${ }^{1, *(D)}$ \\ 1 A.N. Nesmeyanov Institute of Organoelement Compounds, Vavilova Str. 28, 119991 Moscow, Russia; \\ aleksandr.polejaev@gmail.com (A.P.); pavlov@ineos.ac.ru (A.P.); dima.aleshin26@gmail.com (D.A.); \\ savkinasveta91@mail.ru (S.S.); a.teimur1990@gmail.com (T.A.) \\ 2 Kurnakov Institute of General and Inorganic Chemistry, Leninsky prosp. 31, 119991 Moscow, Russia; \\ nnefimov@yandex.ru \\ 3 Bauman Moscow State Technical University, 2nd Baumanskaya Str. 5, 105005 Moscow, Russia \\ 4 Lomonosov Moscow State University, Leninskiye Gory, 1, 119991 Moscow, Russia \\ * Correspondence: unelya@ineos.ac.ru (Y.N.); novikov84@ineos.ac.ru (V.N.); Tel.: +7-499-135-6568 (Y.N.)
}

Received: 14 September 2018; Accepted: 10 October 2018; Published: 16 October 2018

\begin{abstract}
Here we report a series of 1-phenyl-5-substituted 2,6-di(pyrazol-3-yl)pyridine complexes with iron(II) ion found in a high spin state in solids (according to magnetochemistry) and in solution (according to NMR spectroscopy), providing experimental evidence for it being an intramolecular effect induced by the phenyl groups. According to X-ray diffraction, the high spin locking of the metal ion is a result of its highly distorted coordination environment (with a very low 'twist' angle atypical of 2,6-di(pyrazol-3-yl)pyridine complexes), which remains this way in complexes with different substituents and counterions, in a diamagnetic zinc(II) analogue and in their solutions. Three possible reasons behind it, including additional coordination with the phenyl group, energy penalty incurred by its rotation or intramolecular stacking interactions, are addressed experimentally.
\end{abstract}

Keywords: high-spin complexes; iron(II) complexes; molecular design; spin-crossover; spin state trapping; paramagnetic NMR spectroscopy

\section{Introduction}

The ability of some transition metal complexes to exist in two spin states and to switch between them under an applied stimulus (temperature, pressure or light irradiation) [1,2] is behind many concepts of high-density data storage, switching, sensing and other molecular devices and materials [3-5]. Of them, iron(II) complexes with six coordinating nitrogen atoms are often used [1], as the transition occurs between differently colored diamagnetic low-spin (LS, $S=0)$ and paramagnetic high-spin (HS, $S=2$ ) states and is accompanied by large structural changes that promote its cooperativity essential for the above applications [6] Isomeric 2,6-di(pyrazol- $x$-yl)pyridines ( $x=1$ or 3, 1-bpp or 3-bpp) [7,8] are among the most established ligands for this purpose, owing to their synthetic versatility $[7,8]$ and possibility [9] to control the spin state of the metal ion by a judicious choice of substituents.

For complexes $\left[\mathrm{FeL}_{2}\right]^{2+}$ with two meridional tridentate ligands such as bpp or related 2,6-bis(2-pyridyl)pyridine (terpy) [10], the transition from LS to HS state upon heating (or light irradiation [11]) causes distortion of a coordination environment of the metal ion from octahedral towards an edge-bicapped tetrahedron (ebcT), as the M-N distances increase. This distortion (Scheme 1), typically quantified by an angle $\theta$ between the least-squares planes of two ligands ('twist') and a trans $\mathrm{N}-\mathrm{Fe}-\mathrm{N}$ angle $\varphi$ ('rotation') [10], may be so severe as to kinetically trap them in the HS state [12]. Most 
highly distorted structures of $\left[\mathrm{Fe}(\mathrm{bpp})_{2}\right]^{2+}$ found in the HS state (although there are few exceptions [13]) are attributed to crystal packing effects $[12,14]$. However, with a phenyl group at the $\alpha$ position of the pyrazolyl moiety [10], there may be several intramolecular reasons behind it, i.e., the steric crowding [15] of the coordination sphere by the phenyl group (though undermined [16] by its ability to rotate [17] to be accommodated in a complex), additional coordination to the metal ion [18] (as observed for terpy [10]) or energy penalty arising from the above rotation to avoid steric hindrances with the second ligand (as theoretically predicted for 1,3-bpp) [17]. A straightforward explanation by invoking stacking interactions shared by the iron(II) complexes of bpp [19] and terpy (or similar) [20] was termed either as unlikely to cause such a distortion [21] or contributing very little to it [17].

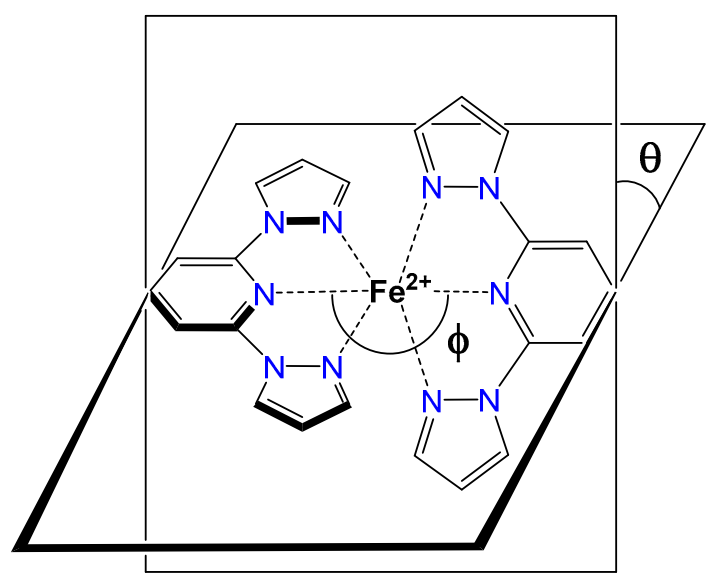

Scheme 1. The parameters of distortion in $\left[\mathrm{Fe}(1-\mathrm{bpp})_{2}\right]^{2+}$ complexes: $149^{\circ} \leq \varphi \leq 180^{\circ}$ and $59^{\circ} \leq \theta \leq$ $90^{\circ}[12]$.

Complexes [Fe(3-bpp $\left.)_{2}\right]^{2+}$, which are much less understood [12] than [Fe(1-bpp) $\left.{ }_{2}\right]^{2+}$ owing to fewer functionalized 3-bpp ligands reported to date [12], are less prone to distortion [22] (typical $\theta$ values $>70^{\circ}$ ) [14] but many of them are still HS only [16,22]. Although uncommon for 3-bpp, a recent iron(II) complex Fe(L1) ${ }_{2} \mathrm{OTf}_{2}$ (L1 = 2,6-di(1-phenyl-5-hydroxy-1H-pyrazol-3-yl)pyridine, Scheme 1), a side-product to $\mathrm{Fe}(\mathbf{L 1}) \mathrm{OTf}_{2}$ for reductive activation of small molecules [23], has a very low value $\theta$ of 64.6-66.5 $5^{\circ}$ at $100 \mathrm{~K}$ according to X-ray diffraction and thus adopts only the HS state, as spin transitions in bpp complexes generally occur at much higher temperatures $[7,8]$.

To get an experimental insight into this HS locking (which may be due to the HS state being thermodynamically more stable than the LS state, as suggested in a computational study for an iron(II) complex 1,3-bpp [17]), we reproduced the ligand L1 (the resulting complex Fe(L1) ${ }_{2} \mathrm{OTf}_{2}$ was obtained as another crystallosolvate [23] but with no significant changes in $\left[\mathrm{Fe}(\mathbf{L 1})_{2}\right]^{2+}$ structure) and synthesized a new one (L2) with acetoxy groups instead of $\mathrm{OH}$ groups (Scheme 2). The two groups have different electron donating/withdrawal ability (as gauged by their Hammett constants [9] and calculated charges [24] of coordinating nitrogen atoms in the free ligands L1 and L2) and therefore exert different electronic effects on the HS/LS stabilization. For iron(II) complexes of 1-bpp, a more electron-withdrawing group at this position of the ligand favors the HS state (mostly through inductive effects [9]). For complexes of 3-bpp, it seems the opposite [12], although not as clear [15] mostly due to them being not as extensively studied as those of 1-bpp [12]. In addition, the bulkier acetoxy group in L2 has no H-donor ability of the hydroxy group, although it can still act as an acceptor of hydrogen bonds, which together with stacking interactions are important for spin state behaviour of transition metal complexes [1], especially with 3-bpp ligands [15]. The new iron(II) complex [Fe(L2) $\left.{ }_{2}\right]^{2+}$ has been synthesized as two salts with triflate and tetrafluoroborate anions $\left.\left(\mathrm{Fe}(\mathbf{L} 2)_{2} \mathrm{OTf}_{2} \text { and } \mathrm{Fe}(\mathbf{L} 2)_{2}(\mathrm{BF})_{2}\right)_{2}\right)$, introducing different perturbations into its crystal environment (similar to different lattice solvents in $\left.\mathrm{Fe}(\mathbf{L 1})_{2} \mathrm{OTf}_{2}\right)$ that should only slightly affect the HS locking and molecular features of $\left[\mathrm{Fe}(\mathbf{L} 2)_{2}\right]^{2+}$ if they are not induced by intermolecular interactions. 


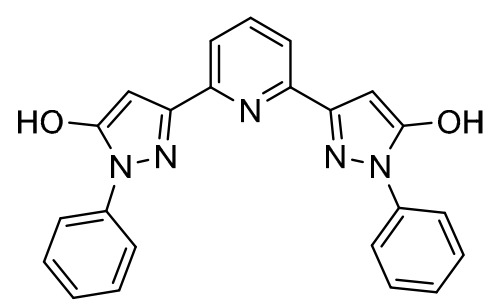

L1

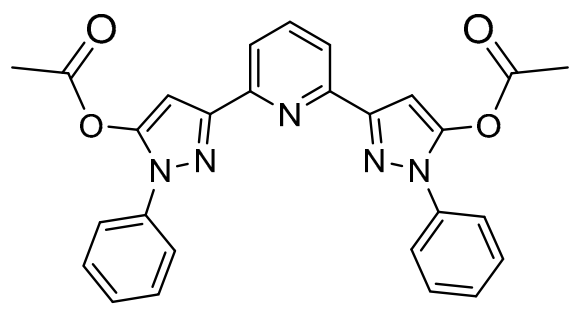

L2

Scheme 2. Ligands in this study: L1, 2,6-di(1-phenyl-5-hydroxy-1H-pyrazol-3-yl)pyridine and L2, 2,6-di(1-phenyl-5-acetoxy-1H-pyrazol-3-yl)pyridine.

The best experimental approach to decouple the spin state from intermolecular effects (and thus to allow for a truly molecular design [15] of spin transition compounds) is to probe it in a solution. Variable-temperature NMR spectroscopy is an easy access for solution studies similar to UV-vis and vibrational spectroscopies, but unlike them, it also allows measuring magnetic susceptibility via the Evans technique $[25,26]$. As its recent alternative (among others [20,27,28]), an approach [29] to the analysis of chemical shifts in NMR spectra, which is assisted by quantum chemistry calculations of spin density and molecular geometry in different spin states (see Materials and Methods), has been proposed for following spin transitions in solutions of paramagnetic compounds with unknown concentrations or admixtures and even obtained in situ (all are well-known limitations of the Evans method) and successfully tested on a series of cobalt(II) complexes of terpy and its derivatives [29]. For iron(II) complexes, such as $\mathrm{Fe}(\mathbf{L} 1)_{2} \mathrm{OTf} f_{2}, \mathrm{Fe}(\mathbf{L} 2)_{2} \mathrm{OTf}_{2}$ and $\mathrm{Fe}(\mathbf{L} 2)_{2}\left(\mathrm{BF}_{4}\right)_{2}$, it measures the population of the paramagnetic HS state over temperature and provides insight into its overall molecular geometry.

In addition, we synthesized a zinc(II) complex $\mathrm{Zn}(\mathbf{L 1})_{2}\left(\mathrm{ClO}_{4}\right)_{2}$ to check how an introduction of a non-spin transition metal ion (that shows no Jahn-Teller effect) would affect the distortion of the complex $\left[\mathrm{M}(\mathbf{L} 1)_{2}\right]^{2+}$ and to identify if it is caused by the ligand design. Diamagnetic analogues of spin transition compounds are not usually structurally analysed [30,31] (e.g., one zinc(II) complex out of a hundred of Fe(II) complexes with 1- or 3-bpp ligands available in CSD, as of 2018), even though they are often used for metal dilution in magnetic measurements and are known to influence the spin state behaviour [32]. They can also be useful as a diamagnetic analogues of the paramagnetic compounds, such as cobalt(II) or HS iron(II) complexes, in an analysis of the NMR data by the recently proposed approach [29].

Here we report how all these modifications to the ligand (L1 or L2), counterion (OTf, $\mathrm{ClO}_{4}$ or $\left.\mathrm{BF}_{4}\right)$, metal ( $\mathrm{Fe}$ or $\mathrm{Zn}$ ) and intermolecular interactions influence the HS state of the complexes $\left[\mathrm{FeL}_{2}\right] \mathrm{X}_{2}$ and a distorted molecular geometry of $\left[\mathrm{ML}_{2}\right]^{2+}$ associated with it and discuss possible reasons behind it by magnetochemistry, X-ray diffraction and multi-temperature NMR spectroscopy.

\section{Results and Discussion}

\subsection{Spin State from Magnetometry}

Spin state of the iron(II) ion in the complexes $\mathrm{Fe}(\mathbf{L} \mathbf{1})_{2} \mathrm{OTf}{ }_{2}, \mathrm{Fe}(\mathbf{L} 2)_{2} \mathrm{OTf}_{2}$ and $\mathrm{Fe}(\mathbf{L} 2)_{2}\left(\mathrm{BF}_{4}\right)_{2}$ has been assessed by variable-temperature $d c$ magnetic susceptibility measurements of their fine-crystalline samples at $3-300 \mathrm{~K}$ (Figure 1). For all of them, $\chi T$ values are constant at $3.7 \mathrm{~cm}^{3} \mathrm{~mol}^{-1} \mathrm{~K}$ between 50 and $300 \mathrm{~K}$, suggesting them to be in the HS state over this entire temperature range. A low-temperature decrease in $\chi T$ and the values $\chi T$ themselves differing from the theoretical pure HS value for $S=2$ $\left(3.00 \mathrm{~cm}^{3} \mathrm{~mol}^{-1} \mathrm{~K}\right)$ result from the zero-field splitting. Modelling these data with PHI software [33] afforded the isotropic value of g-tensor $g_{i s o}$ and the zero-field splitting D equal to 2.18-2.20 and $10.9-13.6 \mathrm{~cm}^{-1}$; the latter being not too low indicates a minor contribution from a 'rotational' distortion, as suggested for the iron(II) complexes of 1-bpp [34]. 


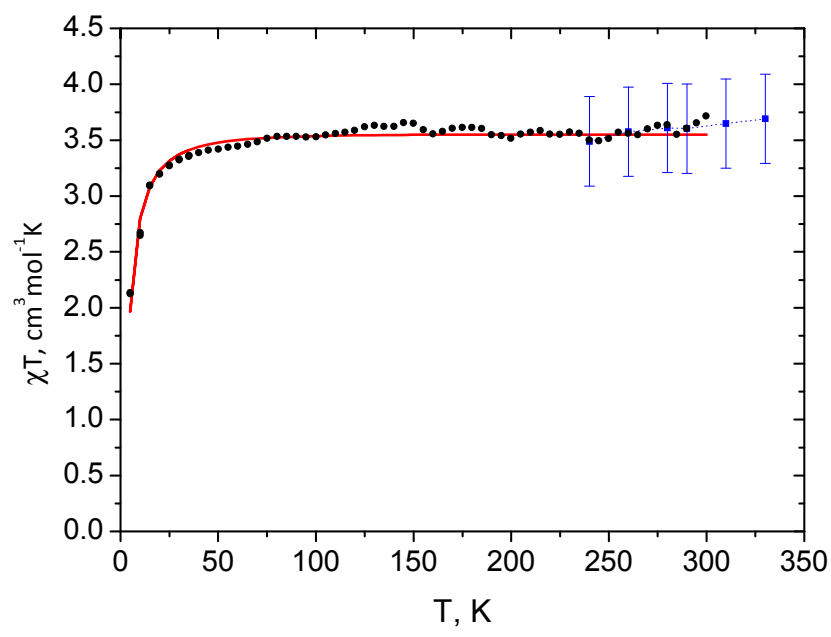

Figure 1. Variable-temperature magnetic susceptibility data for a microcrystalline sample of $\mathrm{Fe}(\mathbf{L 1})_{2} \mathrm{OTf}_{2}$ according to the $d c$-magnetometry $(\bullet)$ and for its acetonitrile- $\mathrm{d}_{3}$ solution according to the Evans method ( $\mathbf{\square})$; for $\mathrm{Fe}(\mathbf{L} 2)_{2} \mathrm{OTf}_{2}$ and $\mathrm{Fe}(\mathbf{L} 2)_{2}\left(\mathrm{BF}_{4}\right)_{2}$, see Figure S1. The red line represents the fit.

\subsection{Spin State from $N M R$}

To exclude solid-state effects behind the observed HS locking, variable-temperature NMR experiments have also been performed for $\mathrm{Fe}(\mathbf{L} \mathbf{1})_{2} \mathrm{OTf}_{2}, \mathrm{Fe}(\mathbf{L} 2)_{2} \mathrm{OTf}_{2}$ and $\mathrm{Fe}(\mathbf{L} 2)_{2}\left(\mathrm{BF}_{4}\right)_{2}$. The ${ }^{1} \mathrm{H} \mathrm{NMR}$ spectra collected from their acetonitrile solutions at 240-330 K show sets of paramagnetically shifted signals that confirm the composition of the obtained iron(II) complexes and their HS state. In addition, these chemical shifts closely follow the linear dependence on temperature as $\delta \sim T^{-1}$ (Figure 2) expected at high T ( $>200 \mathrm{~K}$ ) for systems with a $g$ value close to 2 and a moderate zero-field splitting [35]. As there are no deviations stemming from a spin transition [29] (their other source is large magnetic anisotropy [36-38]), it does not occur between 240 and $330 \mathrm{~K}$. This is quantified by the Evans method [25,26], which measures magnetic susceptibility based on a difference in chemical shifts of an inert substance, e.g., TMS, in a solution of a paramagnetic compound and in a pure solvent recorded simultaneously. Within the experimental error, which is fairly large due to the limitations of the method [29], the resulting $\chi T$ value is constant with temperature at $3.5-4.0 \mathrm{~cm}^{3} \mathrm{~mol}^{-1} \mathrm{~K}$ (Figure 1), thereby corroborating the HS locking of the complexes $\mathrm{Fe}(\mathbf{L} \mathbf{1})_{2} \mathrm{OTf}{ }_{2}, \mathrm{Fe}(\mathbf{L} 2)_{2} \mathrm{OTf}_{2}$ and $\mathrm{Fe}(\mathbf{L} 2)_{2}\left(\mathrm{BF}_{4}\right)_{2}$.

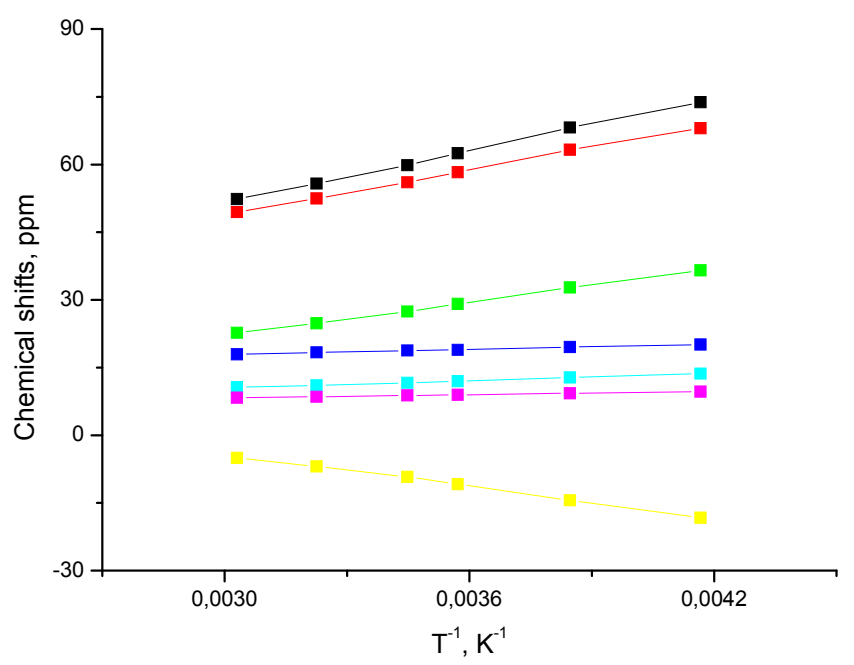

Figure 2. ${ }^{1} \mathrm{H}$ chemical shifts of $\mathrm{Fe}(\mathbf{L 1})_{2} \mathrm{OTf}_{2}$ in an acetonitrile- $\mathrm{d}_{3}$ solution plotted versus $1 / T$; for $\mathrm{Fe}(\mathbf{L} 2)_{2} \mathrm{OTf}_{2}$ and $\mathrm{Fe}(\mathbf{L} 2)_{2}\left(\mathrm{BF}_{4}\right)_{2}$, see Figure S2. The solid lines represent linear fits. 
Analysis of chemical shifts in the NMR spectra of paramagnetic compounds is in the core of another approach [29] that evaluates their spin state population without isolation or purification required for the Evans method. For iron(II) complexes in the paramagnetic HS state, chemical shifts in the NMR spectra at the desired temperature (such as down to $240 \mathrm{~K}$ for acetonitrile) are treated as a sum of diamagnetic $\left(\delta_{\text {dia }}\right)$, contact $\left(\delta_{\mathrm{c}}\right)$ and pseudocontact $\left(\delta_{\mathrm{pc}}\right)$ contributions. The values $\delta_{\text {dia }}$ are directly measured by NMR spectroscopy of a diamagnetic analogue (such as a zinc(II) complex $\mathrm{Zn}(\mathbf{L} \mathbf{1})_{2}\left(\mathrm{ClO}_{4}\right)_{2}$ or a free ligand $\left.\mathbf{L 2}\right)$ at the same temperature, the contact contributions $\delta_{\mathrm{c}}$ are accessed by simple DFT calculations of the paramagnetic complex and the pseudocontact contributions $\delta_{\mathrm{pc}}$ are obtained in a fit of the total chemical shifts $\delta$ to those measured experimentally by varying the value of magnetic susceptibility tensor anisotropy $\Delta \chi_{a x}$ (see Materials and Methods). If combined with NMR spectroscopy on heating/cooling, it provides the population of the HS state over temperature [29]. A good agreement (Figure 3) between the chemical shifts in the ${ }^{1} \mathrm{H}$ NMR spectra of $\mathrm{Fe}(\mathbf{L} 1)_{2} \mathrm{OTf}_{2}$, $\mathrm{Fe}(\mathbf{L} 2)_{2} \mathrm{OTf}_{2}$ and $\mathrm{Fe}(\mathbf{L} 2)_{2}\left(\mathrm{BF}_{4}\right)_{2}$ and those estimated by this approach with molecular geometries of $\left[\mathrm{ML}_{2}\right]^{2+}$ optimized at PBE0/def2-TZVP level of theory or taken from X-ray diffraction data (see below), together with acceptable $\Delta \chi_{a x}$ values [39] resulting from the fit, further confirms their HS state in a solution down to $240 \mathrm{~K}$. All these NMR-based techniques combined show unequivocally that the HS locking in $\mathrm{Fe}(\mathbf{L} 1)_{2} \mathrm{OTf} f_{2}, \mathrm{Fe}(\mathbf{L} 2)_{2} \mathrm{OTf}_{2}$ and $\mathrm{Fe}(\mathbf{L} 2)_{2}\left(\mathrm{BF}_{4}\right)_{2}$ is an intramolecular effect rather than a consequence of crystal packing [12,13].

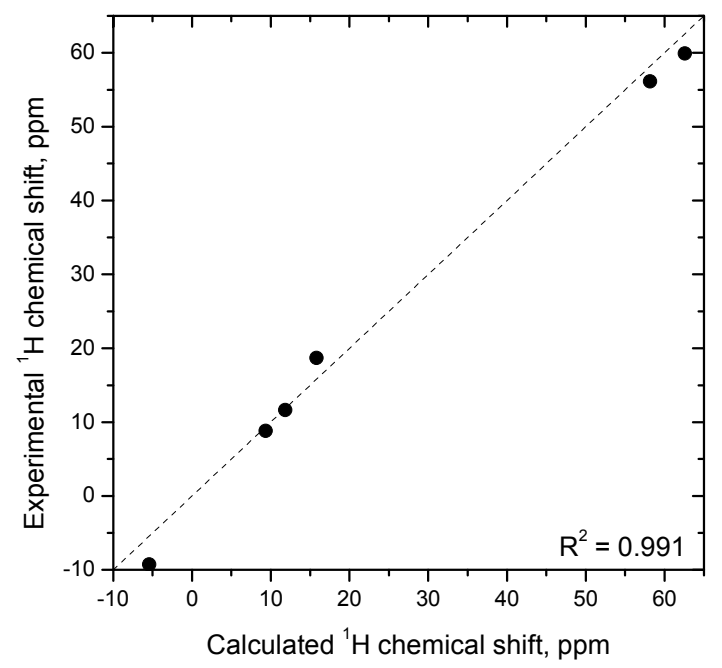

(a)

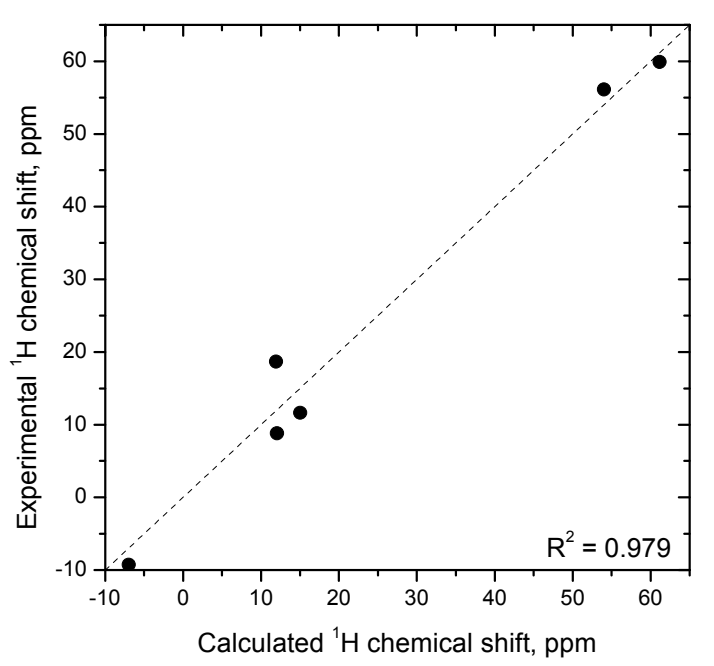

(b)

Figure 3. Correlation plot of experimental vs. theoretical ${ }^{1} \mathrm{H}$ chemical shifts for $\mathrm{Fe}(\mathbf{L 1})_{2} \mathrm{OTf} \mathrm{O}_{2}$ with PBE0-optimized (a) and X-ray geometries (b) of $\left[\mathrm{Fe}(\mathbf{L} 1)_{2}\right]^{2+} ; \Delta \chi_{a x}=7.66 \cdot 10^{-32} \mathrm{~m}^{3}$. For Fe(L2) $)_{2} \mathrm{OTf}{ }_{2}$ and $\mathrm{Fe}(\mathbf{L} 2)_{2}\left(\mathrm{BF}_{4}\right)_{2}$, see Figures S3 and S4.

\subsection{Spin State and Molecular Geometry from X-Ray Diffraction}

It also follows from X-ray diffraction data collected for all the three iron(II) complexes at $120 \mathrm{~K}$ (upon going to this temperature, crystals retained their orange color typical for HS iron(II) complexes [1] and bond lengths Fe-N typical for HS iron(II) complexes of bpp [12]) and of their diamagnetic analogue $\mathrm{Zn}(\mathbf{L 1})_{2}\left(\mathrm{ClO}_{4}\right)_{2}$. Single crystals of a sufficient quality have been obtained with one symmetry-independent $\left[\mathrm{ML}_{2}\right]^{2+}$ species (Figure 4), two counterions and different lattice solvents: diethyl ether in $\mathrm{Fe}(\mathbf{L} 1)_{2} \mathrm{OTf}_{2}$ (instead of acetonitrile in its earlier reported solvatomorph [23]), water and dichloromethane in $\mathrm{Fe}(\mathbf{L} 2)_{2} \mathrm{OTf} f_{2}$, dichloromethane in $\mathrm{Fe}(\mathbf{L} 2)_{2}\left(\mathrm{BF}_{4}\right)_{2}$, diethyl ether with acetonitrile and water in $\mathrm{Zn}(\mathbf{L 1})_{2}\left(\mathrm{ClO}_{4}\right)_{2}$. The latter ensure a very different crystal environment around the complexes $\left[\mathrm{ML}_{2}\right]^{2+}$ in all four cases (Figures S5 and S6). In particular, hydroxy groups of the ligand $\mathbf{L 1}$ form H-bonds with anions in $\mathrm{Fe}(\mathbf{L 1})_{2} \mathrm{OTf}_{2}\left(\mathrm{O} \ldots \mathrm{O} 2.606\right.$ (5)-2.736 (5) $\AA$, OHO 135 (1)-168 (1) $\left.{ }^{\circ}\right)$ but with solvent water molecules in $\mathrm{Zn}(\mathbf{L 1})_{2}\left(\mathrm{ClO}_{4}\right)_{2}(\mathrm{O} \ldots \text {. O } 2.546 \text { (3)-2.641 (3) } \AA \text {, OHO } 155 \text { (1)-178 (1) })^{\circ}$ owing 
to a poorer $\mathrm{H}$-bond acceptor ability of the perchlorate anion. With lattice water also present in the crystal of $\mathrm{Fe}(\mathbf{L} 2)_{2}\left(\mathrm{BF}_{4}\right)_{2}$, one of its acetoxy groups is involved in H-bonds (O . . O 2.988 (5) $\AA$, OHO $\left.160(1)^{\circ}\right)$, which are not observed in $\mathrm{Fe}(\mathbf{L} 2)_{2} \mathrm{OTf}_{2}$. Please note that although each complex has four phenyl groups, they avoid forming intermolecular stacking interactions, just as the pyrazolyl moieties do, so there is no 'terpyridine embrace' motif (Figures S5 and S6) known to play an important role in spin transition behaviour of iron(II) complexes with 1-bpp [40] and 3-bpp [41] ligands.

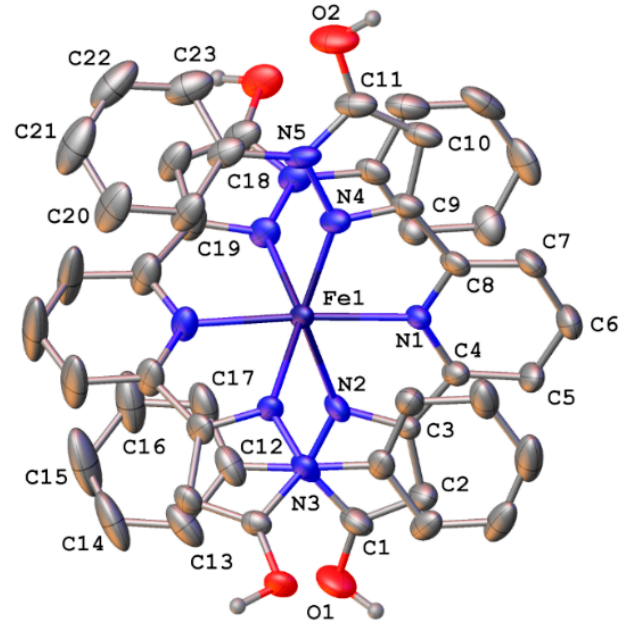

(a)

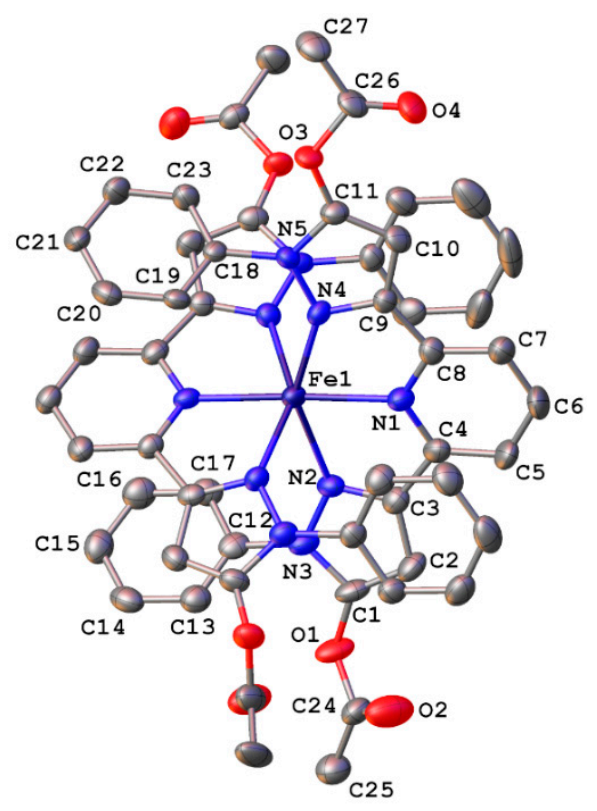

(c)

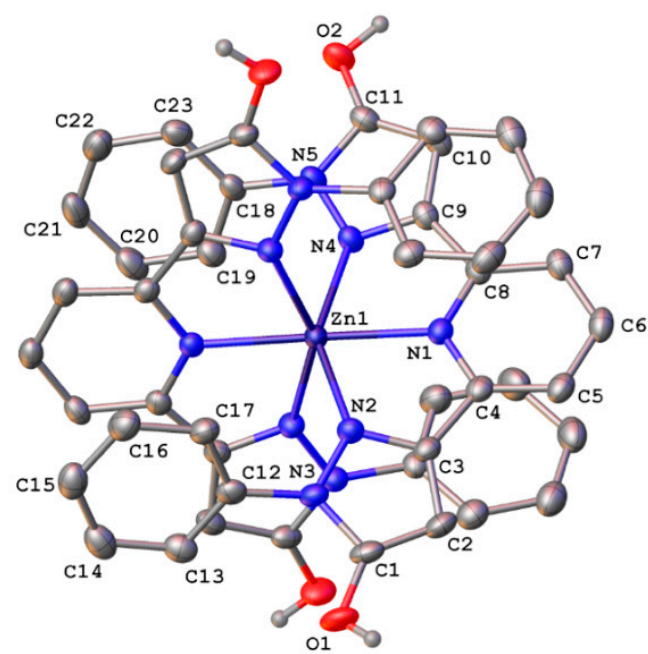

(b)

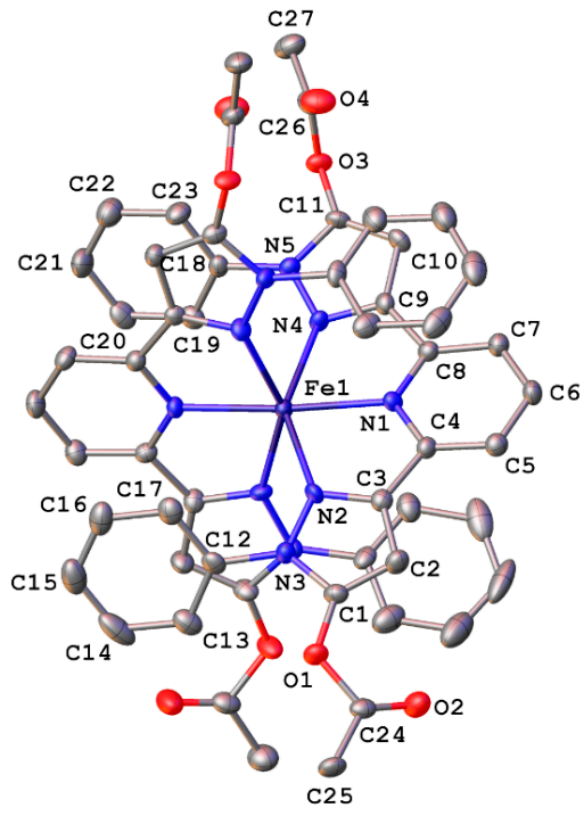

(d)

Figure 4. General view of the $\left[\mathrm{ML}_{2}\right]^{2+}$ cations in $\mathrm{Fe}(\mathbf{L 1})_{2} \mathrm{OTf}_{2}(\mathbf{a}), \mathrm{Zn}(\mathbf{L 1})_{2}\left(\mathrm{ClO}_{4}\right)_{2}(\mathbf{b}), \mathrm{Fe}(\mathbf{L} 2)_{2} \mathrm{OTf}_{2}$ (c) and $\mathrm{Fe}(\mathbf{L} 2)_{2}\left(\mathrm{BF}_{4}\right)_{2}(\mathbf{d})$, with atoms shown as thermal ellipsoids ( $\left.p=30 \%\right)$. Hydrogen atoms, except those of the hydroxy groups in $\mathrm{Fe}(\mathbf{L 1})_{2} \mathrm{OTf}_{2}$ and $\mathrm{Zn}(\mathbf{L} \mathbf{1})_{2}\left(\mathrm{ClO}_{4}\right)_{2}$, are omitted for clarity.

Despite different crystal packing effects on $\left[\mathrm{ML}_{2}\right]^{2+}$, nature of the ligands and even of the metal ions, all four complexes have a similarly distorted coordination geometry (Table 1). This distortion can be described by easily accessible angles $\varphi$ and $\theta$, the measures of 'rotation' $\left(\varphi<180^{\circ}\right)$ and 'twist' $\left(\theta<90^{\circ}\right)$ component [10] that are independent from each other. For iron(II) complexes of 1-bpp, they are rather good indicators of a spin transition to the LS state [8], which in general [13] does not occur if $\varphi<172^{\circ}$ and / or $\theta<76^{\circ}$. In $\mathrm{Fe}(\mathbf{L 1})_{2} \mathrm{OTf}_{2}, \mathrm{Fe}(\mathbf{L} 2)_{2} \mathrm{OTf}_{2}$ and $\mathrm{Fe}(\mathbf{L} 2)_{2}\left(\mathrm{BF}_{4}\right)_{2}$, the $\theta$ values are all below 
$70^{\circ}$ (66.7-69.8 $8^{\circ}$ with the value for the diamagnetic zinc(II) complex in between). Given that this is very low for the iron(II) complexes with 3-bpp ligands [14], they should almost [13] certainly be locked in the HS state, as evidenced by the variable-temperature magnetochemistry and NMR measurements. Their $\varphi$ values are, on the other hand, close to $180^{\circ}$, so a major contribution to the distortion comes from the 'twist' component, which is consistent with the zero-field splitting parameters [34].

Table 1. Main geometric parameters and continuous symmetry measures as obtained by X-ray diffraction. ${ }^{1}$

\begin{tabular}{ccccc}
\hline & $\mathbf{F e}(\mathbf{L 1})_{\mathbf{2}} \mathbf{O T f}_{\mathbf{2}}$ & $\mathbf{Z n}(\mathbf{L 1})_{\mathbf{2}}\left(\mathbf{C l O}_{\mathbf{4}}\right)_{\mathbf{2}}$ & $\mathbf{F e}(\mathbf{L} 2)_{\mathbf{2}} \mathbf{O T f}_{\mathbf{2}}$ & $\mathbf{F e}(\mathbf{L 2})_{\mathbf{2}} \mathbf{( B F}_{\mathbf{4}} \mathbf{2}_{\mathbf{2}}$ \\
\hline $\mathrm{M}-\mathrm{N}(1), \AA$ & $2.132(3)$ & $2.116(2)$ & $2.130(5)$ & $2.145(4)$ \\
$\mathrm{M}-\mathrm{N}(1 \mathrm{~A}), \AA$ & $2.140(4)$ & $2.115(2)$ & $2.131(5)$ & $2.144(4)$ \\
$\mathrm{M}-\mathrm{A}(2), \AA$ & $2.213(4)$ & $2.171(2)$ & $2.263(5)$ & $2.207(5)$ \\
$\mathrm{M}-\mathrm{A}(2 \mathrm{~A}), \AA$ & $2.234(3)$ & $2.171(2)$ & $2.220(5)$ & $2.229(5)$ \\
$\mathrm{M}-\mathrm{A}(4), \AA$ & $2.231(4)$ & $2.172(2)$ & $2.206(5)$ & $2.223(4)$ \\
$\mathrm{M}-\mathrm{N}(4 \mathrm{~A}), \AA$ & $2.171(4)$ & $2.189(2)$ & $2.235(5)$ & $2.230(5)$ \\
$\theta^{\circ}$ & 67.5 & 69.4 & 66.7 & 69.8 \\
$\varphi^{\circ}$ & 176.1 & 178.9 & 177.4 & 175.5 \\
$\mathrm{~S}\left(\mathrm{O}_{\mathrm{h}}\right)$ & 6.12 & 5.30 & 6.02 & 6.33 \\
$\mathrm{~S}(\mathrm{itp})$ & 10.49 & 11.08 & 10.98 & 10.52 \\
$\mathrm{~S}(\mathrm{ebcT})$ & 9.015 & 9.011 & 9.402 & 8.849 \\
\hline$\gamma^{\circ}$ & $50.1 / 42.7$ & $56.3 / 57.0$ & $47.8 / 60.3$ & $49.9 / 59.4$ \\
$\beta^{\circ}$ & $46.2 / 60.5$ & $66.4 / 58.9$ & $50.3 / 55.7$ & $53.1 / 63.4$ \\
\hline & $10.7 / 10.6$ & $7.7 / 6.9$ & $9.0 / 8.0$ & $4.4 / 13.1$ \\
\hline
\end{tabular}

${ }^{1} \theta$ is the angle between the two least-squares planes of the 3-bpp ligands; $\varphi$ is the trans angle N-M-N; S(Oh), S(itp) and $\mathrm{S}(\mathrm{ebcT})$ are octahedral, trigonal prismatic and edge-bicapped tetrahedral symmetry measures, respectively; $\gamma$ is the rotation angle of the phenyl group relative to the pyrazol-3-yl plane; $\beta$ is the angle between the least-squares planes of the phenyl group of one ligand and the pyridyl group of the other.

\subsection{Molecular Geometry from NMR}

Such a distorted molecular geometry even remains in solutions, as supported by the above NMR-based approach [29] applied to the iron(II) complexes. To exclude solid-state effects in this approach, spin density calculations for assessing the contact contributions of the chemical shifts were performed for PBE0-optimized geometries. For the HS complexes $\left[\mathrm{Fe}(\mathbf{L} 1)_{2}\right]^{2+}$ and $\left[\mathrm{Fe}(\mathbf{L} 2)_{2}\right]^{2+}$ in acetonitrile (a solvent used in the NMR experiments), they closely reproduced those from the X-ray diffraction, e.g., the bond lengths Fe-N (2.117-2.252 $⿱$ ) $)$, the values of $\varphi\left(179.3\right.$ and $\left.177.5^{\circ}\right)$ and $\theta$ $\left(72.5\right.$ and $\left.68.5^{\circ}\right)$. A good agreement between the chemical shifts in the ${ }^{1} \mathrm{H}$ NMR spectra of $\mathrm{Fe}(\mathbf{L 1})_{2} \mathrm{OTf}_{2}$, $\mathrm{Fe}(\mathbf{L} 2)_{2} \mathrm{OTf}_{2}$ or $\mathrm{Fe}(\mathbf{L} 2)_{2}\left(\mathrm{BF}_{4}\right)_{2}$ and their estimates based on both types of molecular geometries used to calculate contact contributions and to fit the pseudocontact ones for $\left[\mathrm{Fe}(\mathbf{L} 1)_{2}\right]^{2+}$ and $\left[\mathrm{Fe}(\mathbf{L} 2)_{2}\right]^{2+}$ (Figure 3 and Figures S3 and S4) is a good indication that these iron(II) complexes are similarly distorted in solution.

\subsection{Distortion of Molecular Geometry from Symmetry Measures}

A better descriptor of this distortion (and another good indicator of the spin state [42]) is continuous symmetry measures (Table 1) [10]. They measure how close the shape of the coordination polyhedron of a metal ion fits the ideal polyhedron, e.g., it should be zero for an ideal octahedron (OC-6) or an ideal trigonal prism (TRP-6). For iron(II) complexes with a N6 donor set, the transition from LS to HS state upon raising the temperature is associated with a trigonal twist distortion (the Bailar twist) from octahedral geometry [42]. The symmetry measures for $\mathrm{Fe}(\mathbf{L 1})_{2} \mathrm{OTf}{ }_{2}, \mathrm{Fe}(\mathbf{L} 2)_{2} \mathrm{OTf}_{2}$ and $\mathrm{Fe}(\mathbf{L} 2)_{2}\left(\mathrm{BF}_{4}\right)_{2}$ are significantly removed from this pathway (Figure $5 \mathrm{a}$ ), as typical of iron(II) complexes with tridentate ligands spanning mer positions (such as bpp or terpy) owing to the constrains imposed by these rigid ligands [14]. The corresponding S(OC-6) and S(TRP-6) values, which nicely overlap for NMR (PBE0-optimized) and X-ray (experimental) geometries (Figure 5), fall into the range of HS only 
for iron(II) complexes with both 1-bpp [12] and 3-bpp [14] ligands. Surprisingly, $\mathrm{Zn}(\mathbf{L 1})_{2}\left(\mathrm{ClO}_{4}\right)_{2}$ is not an exception, although its coordination geometry is slightly shifted towards an octahedron (similar to the isolated $\left[\mathrm{Fe}(\mathbf{L} 1)_{2}\right]^{2+}$ and $\left[\mathrm{Fe}(\mathbf{L} 2)_{2}\right]^{2+}$ in the HS state). This behaviour indicates a $\mathrm{D}_{2} \mathrm{~d}$ double axial distortion common for the iron(II) complexes of terpy [43] and both families of bpp ligands [12], with a geometry of the HS state deformed toward an edge-bicapped tetrahedron (ebcT-6) [10]. Such a distortion of the zinc(II) complex, however, cannot be explained by the $\mathrm{Zn}-\mathrm{N}$ bond lengths being close to those of the HS iron(II) ion, as the zinc(II) ion has a more octahedral-like coordination environment in other complexes of bpp available in Cambridge structural database, CSD (see, e.g., refcodes JIZCUS [44], YODNOW [32], YODNUC [32], XEGFEU [30] and XIMSIV [31]).

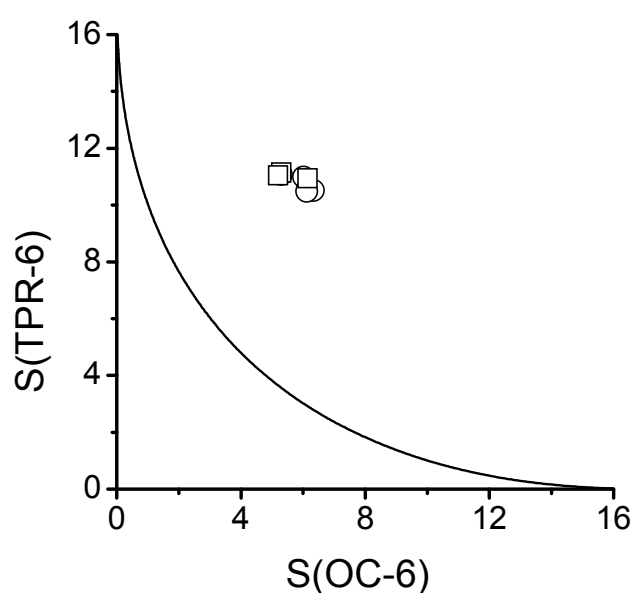

(a)

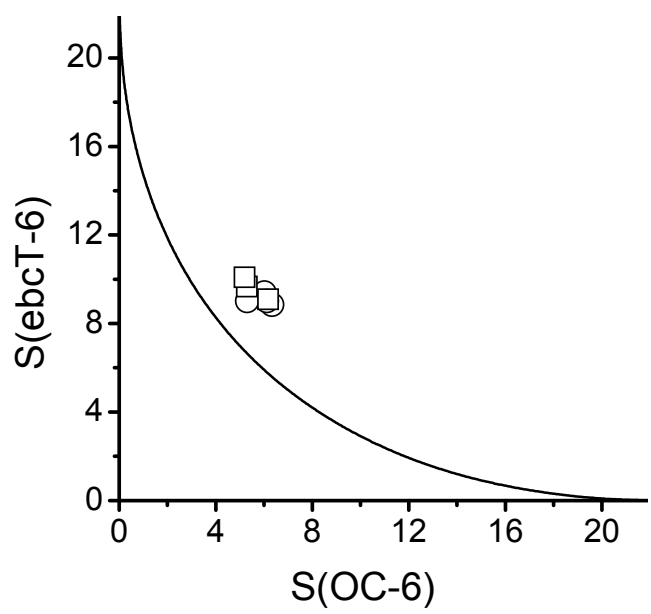

(b)

Figure 5. Shape maps for $\mathrm{Fe}(\mathbf{L} 1)_{2} \mathrm{OTf} f_{2}, \mathrm{Zn}(\mathbf{L 1})_{2}\left(\mathrm{ClO}_{4}\right)_{2}, \mathrm{Fe}(\mathbf{L} 2)_{2} \mathrm{OTf}_{2}$ and $\mathrm{Fe}(\mathbf{L} 2)_{2}\left(\mathrm{BF}_{4}\right)_{2}$ that show octahedral S(OC-6) symmetry measure plotted against trigonal prismatic S(TRP-6) (a) and edge-bicapped tetrahedral S(ebcT-6) (b) symmetry measures. Continuous lines represent minimum distortion pathway between the reference polyhedra, open circles and squares correspond to the coordination geometry according to X-ray diffraction (Table 1) and NMR-based approach, respectively.

If referenced to OC-6 and ebcT-6 (Figure 5b), the four complexes feature a rather small deviation from this, more accurate pathway [10] towards a vacant cape trigonal prism (as found for the HS complexes of $\left[\mathrm{Fe}(\text { terpy })_{2}\right]^{2+}$ with phenyl, p-tolyl or pyridyl groups at $\alpha$-positions [10]) or towards a divacant bicapped trigonal prism (as found for some bpp complexes [10]). In all those cases, the deviations were attributed to weak additional coordination of the metal centre either by the above phenyl (p-tolyl or pyridyl) substituent [10] or by outer-sphere anions [12].

\subsection{Distortion of Molecular Geometry by Secondary Interactions}

There is, however, very little indication that the metal ion in $\mathrm{Fe}(\mathbf{L} 1)_{2} \mathrm{OTf}_{2}, \mathrm{Fe}(\mathbf{L} 2)_{2} \mathrm{OTf}_{2}$, $\mathrm{Fe}(\mathbf{L} 2)_{2}\left(\mathrm{BF}_{4}\right)_{2}$ or $\mathrm{Zn}(\mathbf{L 1})_{2}\left(\mathrm{ClO}_{4}\right)_{2}$ is involved in any of these secondary interactions. The outer-sphere species (such as anions or solvate molecules) in their crystals are too far away from the metal ion (>4.9 $\AA$ ), and it would disagree with the distortion being an intramolecular effect as follows from the above NMR data. Coordination by the phenyl groups may be suspected only if the shortest $\mathrm{M}$ ... C distances $\left(3.73,3.81\right.$ and $3.67 \AA$ for $\mathrm{Fe}(\mathbf{L} 1)_{2} \mathrm{OTf}_{2}, \mathrm{Fe}(\mathbf{L} 2)_{2} \mathrm{OTf}_{2}$ and $\mathrm{Fe}(\mathbf{L} 2)_{2}\left(\mathrm{BF}_{4}\right)_{2}$ vs. $3.81 \AA$ for $\left.\mathrm{Zn}(\mathbf{L 1})_{2}\left(\mathrm{ClO}_{4}\right)_{2}\right)$ are compared to the sum of the van-der-Waals radii of Alvarez (4.21 and $4.16 \AA$ for Fe ... C and Zn ... C contacts) [18]; relative to more conventional radii of Bondi [45] (2.09 $\AA$ for $\mathrm{Zn}$ .. C) or Batsanov [46] (3.75 and $3.8 \AA$ for Fe .. . C and Zn .. C, respectively), they are too long for such an interaction to occur. In addition, these distances do not correlate with the average Fe-N distances, as in some of $\left[\mathrm{Fe}(1-\mathrm{bpp})_{2}\right]^{2+}$ complexes [47], nor there is an elongation of the opposite Fe-N bonds [10], as caused by secondary coordination with a phenyl or similar group in $\left[\mathrm{Fe}(\mathrm{terpy})_{2}\right]^{2+}$. 
Therefore, the observed distortion of coordination geometry in $\mathrm{Fe}(\mathbf{L} \mathbf{1})_{2} \mathrm{OTf} \mathrm{f}_{2}, \mathrm{Fe}(\mathbf{L} 2)_{2} \mathrm{OTf}{ }_{2}, \mathrm{Fe}(\mathbf{L} 2)_{2}\left(\mathrm{BF}_{4}\right)_{2}$ and $\left.\mathrm{Zn}(\mathbf{L 1})_{2}\left(\mathrm{ClO}_{4}\right)_{2}\right)$ and the related HS locking of the iron(II) complexes are not associated with the existence of such weak coordinating interactions; the energy penalty to rotation of the phenyl groups [17] is a more likely reason for it.

\subsection{Rotation of Phenyl Groups}

According to $\mathrm{X}$-ray diffraction, the phenyl groups in all the four complexes are rotated relative to the pyrazol-3-yl planes (Figure 6) by $42.7^{\circ}$ in $\mathrm{Fe}(\mathbf{L 1})_{2} \mathrm{OTf}_{2}$ (slightly higher than in its early solvatomorph [23]) to $66.4^{\circ}$ in $\mathrm{Zn}(\mathbf{L 1})_{2}\left(\mathrm{ClO}_{4}\right)_{2}$, the average angle between the two planes being 49.9, 53.5 and $56.5^{\circ}$ in $\mathrm{Fe}(\mathbf{L 1})_{2} \mathrm{OTf}_{2}, \mathrm{Fe}(\mathbf{L} 2)_{2} \mathrm{OTf}_{2}$ and $\mathrm{Fe}(\mathbf{L} 2)_{2}\left(\mathrm{BF}_{4}\right)_{2}$ and $59.7^{\circ}$ in $\mathrm{Zn}(\mathbf{L} 1)_{2}\left(\mathrm{ClO}_{4}\right)_{2}$. A similar rotation of the phenyl group but relative to the pyrazol-1-yl moiety in the iron(II) complex of 1,3-bpp (by 45.3-49.2 ${ }^{\circ}$ [17] has previously been proposed to result mainly from avoiding steric hindrances with the second ligand (although interligand stacking interactions were also found to contribute slightly to the stability of a likewise distorted HS state) [17]. It was computationally shown to cause an energetic penalty associated with the loss of planarity in the phenyl-pyrazol-1-yl moiety, preventing the complexes from adopting an undistorted LS state in which the phenyl groups are nearly perpendicular to the pyrazolyl plane. However, the derivatives of 3-bpp may feature a different behaviour when compared to 1-bpp (as hinted by an observed opposite trend in the influence of electron donating/withdrawing substituents on the spin state of iron(II) complexes) [12,15].
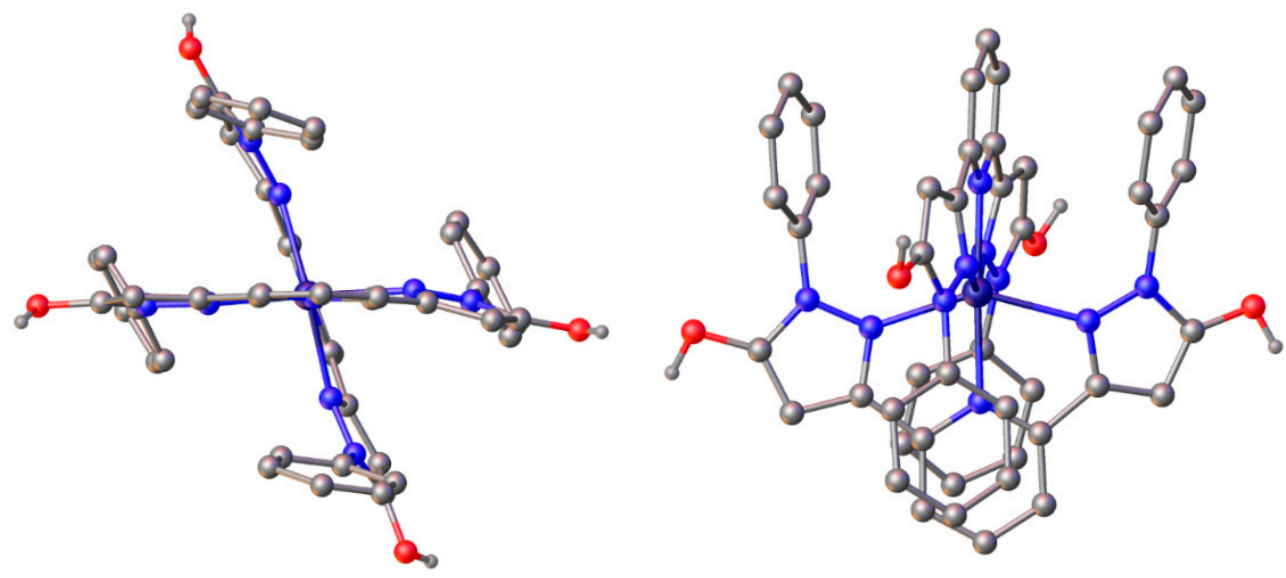

Figure 6. Two projections of the cation $\left[\mathrm{Fe}(\mathrm{L})_{2}\right]^{2+}$ in $\mathrm{Fe}(\mathbf{L} \mathbf{1})_{2} \mathrm{OTf} f_{2}$.

Indeed, the phenyl groups in free 3-bpp ligands available in CSD (refcodes ILESUP and GETSUL) [23] are already rotated by $28-43^{\circ}$, and in a rare case of $\mathrm{M}(\mathrm{L}) \mathrm{X}_{2}$ complexes (refcodes GECSEP and GESCIP) [23], by up to $\sim 35^{\circ}$. In the 1-bpp ligand with the phenyl groups at the same position (2,6-bis(5-(4-Methoxyphenyl)-3-phenyl-1H-pyrazol-1-yl)pyridine, SUPZIN), the corresponding angles are $\sim 14$ and $28^{\circ}$. Moreover, an analysis of CSD for all the ordered organic compounds that contain a phenyl-pyrazol-1-yl or a phenyl-pyrazol-3-yl fragment (Figure S7) shows that the angle between the two planes in the case of the latter adopts a wider variety of values with a maximum at $\sim 40^{\circ}$, while the former are clustered around $0^{\circ}$. Their behaviour mirrors calculated energy variation upon the rotation of the phenyl group in the corresponding phenylpyrazole molecules [17] and suggests that the 3-bpp ligands have a lower penalty to their rotation (Figure 7).

In $\mathrm{Fe}(\mathbf{L 1})_{2} \mathrm{OTf}_{2}, \mathrm{Fe}(\mathbf{L} 2)_{2} \mathrm{OTf}_{2}$ and $\mathrm{Fe}(\mathbf{L} 2)_{2}\left(\mathrm{BF}_{4}\right)_{2}$, however, the phenyl groups rotate to higher angles than in an isomeric $\left[\mathrm{Fe}\left(\mathrm{Ph}_{2}-1-\mathrm{bpp}\right)_{2}\right]^{2+}\left(32.4-36.5^{\circ}\right)[34]$ or the above $\left[\mathrm{Fe}\left(\mathrm{Ph}_{2}-1,3-\mathrm{bpp}\right)_{2}\right]^{2+}$ $\left(45.3-49.2^{\circ}\right)$ [17], in which they follow the degree of the 'twist' distortion as gauged by the $\theta$ values $(\sim 61$ and $70^{\circ}$, respectively; Figure S8); no statistically significant correlation between these two parameters was observed. Given the initially higher rotation angles in the HS state (and a generally lower energy variation upon the rotation; Figure 7), it should be easier for the iron(II) complexes with 
the phenyl-substituted 3-bpp ligands to go to an undistorted LS state. Indeed, according to our PBE0/def2-TZVP calculation for a model complex $\left[\mathrm{Fe}\left(\mathrm{Ph}_{2}-3-\mathrm{bpp}\right)_{2}\right]^{2+}$ (see Materials and Methods), the energy penalty of rotating four phenyl groups from the angles they from in a HS state (42.1, $44.3,47.9$ and $\left.50.3^{\circ}\right)$ to those in a LS state $\left(69.3,83.8,85.7\right.$ and $\left.88.1^{\circ}\right)$ is theoretically estimated to be only half of the energy difference between the spin states $(7.3 \mathrm{vs} .15 .8 \mathrm{kcal} / \mathrm{mol})$, indicating the stabilization of a likewise distorted HS structure $\left(\theta=65.6^{\circ}\right.$ and $\varphi=177.6^{\circ} ; \mathrm{M}-\mathrm{N}$ of $\left.2.113-2.225 \AA\right)$ over an undistorted LS one $\left(\theta=87.0^{\circ}\right.$ and $\varphi=178.7^{\circ} ; \mathrm{M}-\mathrm{N}$ of $\left.1.928-2.021 \AA\right)$ in acetonitrile used as a solvent in NMR experiments.

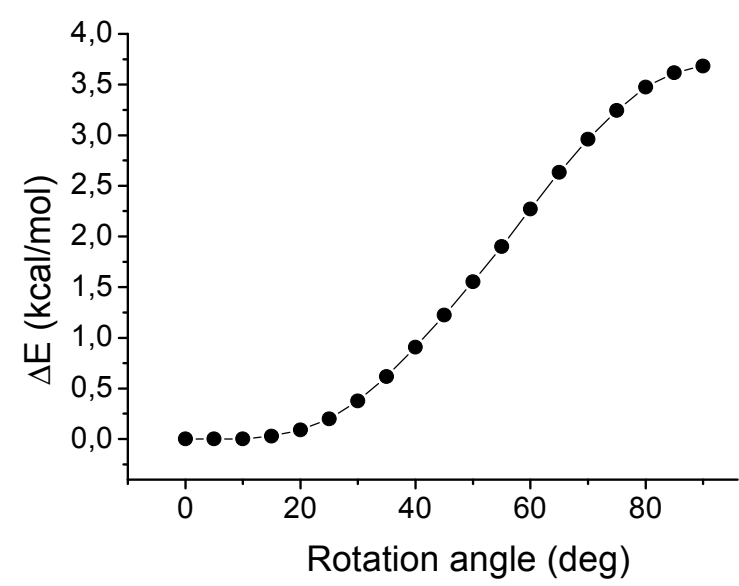

(a)

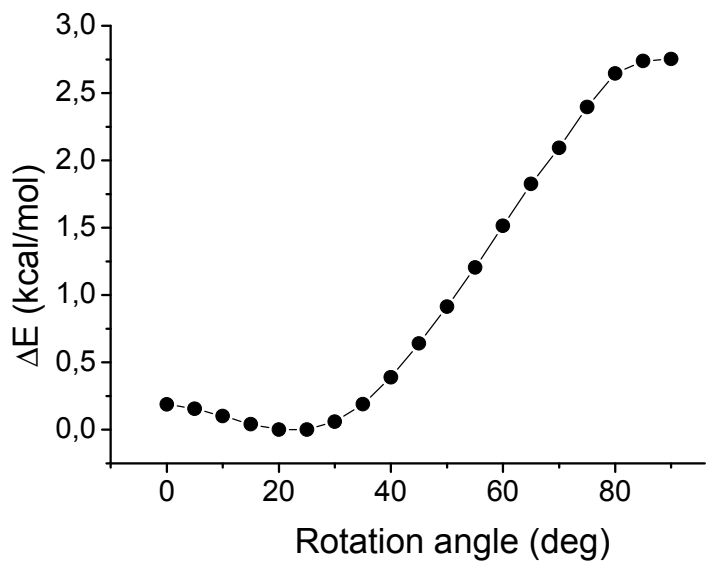

(b)

Figure 7. Energy variation upon the rotation of the phenyl group relative to pyrazol-x-yl in phenyl-pyrazol-1-yl (a) and phenyl-pyrazol-3-yl (b) according to PBE0/def2-TZVP calculation (see Materials and Methods).

\subsection{Stacking Interactions}

Additional contribution to the HS locking in $\mathrm{Fe}(\mathbf{L 1})_{2} \mathrm{OTf}_{2}, \mathrm{Fe}(\mathbf{L} 2)_{2} \mathrm{OTf}_{2}$ and $\mathrm{Fe}(\mathbf{L} 2)_{2}\left(\mathrm{BF}_{4}\right)_{2}$ by the phenyl groups may come from stabilization of a distorted molecular geometry by intramolecular stacking interactions, which all the four complexes have in common. Thus, the phenyl groups are significantly rotated to the plane of the pyrazol-3-yl moieties, but are nearly parallel to the pyridine ring of the second ligand, as in an earlier solvatomorph of $\mathrm{Fe}(\mathbf{L 1})_{2} \mathrm{OTf}_{2}$ [23]. The angles between the planes are $4.4-16.1^{\circ}$ (Table 1 ) with those in $\mathrm{Zn}(\mathbf{L 1})_{2}\left(\mathrm{ClO}_{4}\right)_{2}$ being on a smaller side $\left(7.4^{\circ}\right.$ on average vs. $13.2,11.8$ and $10.2^{\circ}$ in $\mathrm{Fe}(\mathbf{L} 1)_{2} \mathrm{OTf} f_{2}, \mathrm{Fe}(\mathbf{L} 2)_{2} \mathrm{OTf}_{2}$ and $\left.\mathrm{Fe}(\mathbf{L} 2)_{2}\left(\mathrm{BF}_{4}\right)_{2}\right)$. The zinc(II) complex, however, does not stand out if the shortest $\mathrm{C}$... C distances are considered (3.413-3.667 $\AA$ ); their average being 3.477, 3.553 and $3.499 \AA$ in $\mathrm{Fe}(\mathbf{L 1})_{2} \mathrm{OTf} f_{2}, \mathrm{Fe}(\mathbf{L} 2)_{2} \mathrm{OTf}_{2}$ and $\mathrm{Fe}(\mathbf{L} 2)_{2}\left(\mathrm{BF}_{4}\right)_{2}$ and $3.566 \AA$ in $\mathrm{Zn}(\mathbf{L 1})_{2}\left(\mathrm{ClO}_{4}\right)_{2}$. These stacking interactions bind the phenyl and pyridine groups in a so-called 'parallel-displaced' orientation [48] (Figure 6), which is significantly preferred (over 'face-to-face' when the two groups are parallel, or 'T-shaped' when they are perpendicular to each other) for stacking interactions between benzene and pyridine molecules [49]; the binding energy may be as high as $3 \mathrm{kcal} / \mathrm{mol}$ at similar intermolecular separations.

The complexes keep the same orientation (with the phenyl groups slightly displaced towards the pyrazol-3-yl moiety) in solution, as hinted by a good correlation between the calculated chemical shifts and those measured experimentally for the HS iron(II) complexes, and is supported by chemical shifts for $\mathrm{Zn}(\mathbf{L 1})_{2}\left(\mathrm{ClO}_{4}\right)_{2}$ (Figures S9 and S10) and, more suited for this purpose, ROESY NMR data (Figure S11). Signals of the protons of the phenyl and pyridine groups in its ${ }^{1} \mathrm{H}$ NMR spectra (Figures S9 and S10) are shifted to higher field as compared to the free ligand L1, which is consistent with the shielding expected if these groups are involved in a 'parallel-displaced' stacking interaction. In the ROESY spectrum of $\mathrm{Zn}(\mathbf{L 1})_{2}\left(\mathrm{ClO}_{4}\right)_{2}$ (Figure S11), the cross-peaks appear between the nuclei of the phenyl and pyridine groups, which are separated by more than $7 \AA$ in the ligand but closely approach each other 
in the complex. The observed cross-peaks agree well with the molecular geometry as obtained by X-ray diffraction for $\mathrm{Zn}(\mathbf{L 1})_{2}\left(\mathrm{ClO}_{4}\right)_{2}$.

Another complex of 3-bpp with pendant phenyl groups available in CSD, a heteroleptic ruthenium(II) complex with two thriphenylphosphine molecules (refcode UZEHIR) [50], also features a 'parallel-displaced' stacking interaction between the 3-bpp ligand and one of the phenyl groups of both of its $\mathrm{PPh}_{3}$. Moreover, the iron(II) complexes of 1-bpp [34], 1,3-bpp [17] and even of terpy [51-54] with the phenyl or related groups (such as p-tolyl [51], metoxyphenyl [53] or pyridyl [54]), despite clearly having different potential to their rotation, all suffer from similar 'twist' distortions with the $\theta$ values from $58.8^{\circ}$ [51] to $76.5^{\circ}$ [54], feature 'parallel-displaced' intramolecular stacking interactions (Figure S8) and are HS (the exception being mesityl-substituted complexes of 1-bpp [19] and terpy [51] locked in their LS state either due to inductive [19] or steric [17] properties of the mesityl group).

A final piece of experimental evidence for an important role of intramolecular stacking interactions in the stabilization of a distorted molecular geometry of $\left[\mathrm{ML}_{2}\right]^{2+}$ is based on a tendency of the 3-bpp ligands to form heteroleptic iron(II) complexes with terpy in solution [55]. Mixing equimolar quantities of $\mathbf{L 1}, \mathrm{FeCl}_{2}$ and terpy in different solvents (methanol, DMSO and acetonitrile) did not result in the formation of a heteroleptic complex; only a mixture of $\left[\mathrm{Fe}(\mathbf{L} \mathbf{1})_{2}\right] \mathrm{Cl}_{2}$ (with a metal ion in the HS state as gauged by the paramagnetic shifts) and diamagnetic $\left[\mathrm{Fe}(\text { terpy })_{2}\right] \mathrm{Cl}_{2}$ was always observed (Figure S12). Efforts to combine the two (L1 favoring the HS state and terpy favoring the LS state [55] of iron(II) ion) in one complex to 'unlock' the spin transition are underway in our group.

\section{Materials and Methods}

Synthesis. All synthetic manipulations were carried out in air. Solvents were purchased from commercial sources, purified using Innovative Technology SPS-400 PureSolv solvent system or by distilling from conventional drying agents and degassed by the freeze-pump-thaw method twice prior to use; THF was stored over activated $4 \AA$ molecular sieves or sodium metal pieces. The compounds $\mathbf{L 1}$ and $\mathrm{Fe}(\mathbf{L 1})_{2} \mathrm{OTf}_{2}$ were synthesized as previously reported [23].

Ligand L2. Compound L1 (395 mg, $0.1 \mathrm{mmol}$ ) was dispersed in $10 \mathrm{ml}$ of THF, and $1 \mathrm{~mL} \mathrm{of} \mathrm{Et}_{3} \mathrm{~N}$ was added. The mixture was cooled down to $-15^{\circ} \mathrm{C}$ using an ice-salt bath, and $151 \mu \mathrm{L}(0.21 \mathrm{mmol})$ of $\mathrm{AcCl}$ was added dropwise using a micro syringe. After warming up to r.t., the reaction mixture was stirred for additional $12 \mathrm{~h}$. Reaction mixture was then filtered from ammonium salt, and volatiles were removed under vacuum to give light-yellow fine-crystalline solid. Yield $405 \mathrm{mg}(85 \%) .{ }^{1} \mathrm{H} \mathrm{NMR}$ $\left(400 \mathrm{MHz}, 25^{\circ} \mathrm{C}, \mathrm{CDCl}_{3}\right): \delta(\mathrm{ppm})=8.07\left(\mathrm{~d}, J_{\mathrm{H}, \mathrm{H}}=7.8 \mathrm{~Hz}, 2 \mathrm{H}\right), 7.78\left(\mathrm{t}, J_{\mathrm{H}, \mathrm{H}}=8.3 \mathrm{~Hz}, 1 \mathrm{H}\right), 7.66(\mathrm{~d}$, $\left.J_{\mathrm{H}, \mathrm{H}}=7.8 \mathrm{~Hz}, 4 \mathrm{H}\right), 7.49\left(\mathrm{t}, J_{\mathrm{H}, \mathrm{H}}=7.8 \mathrm{~Hz}, 4 \mathrm{H}\right), 7.38\left(\mathrm{t}, J_{\mathrm{H}, \mathrm{H}}=6.9 \mathrm{~Hz}, 2 \mathrm{H}\right), 7.07(\mathrm{~s}, 2 \mathrm{H}), 2.30(\mathrm{~s}, 6 \mathrm{H})$. ${ }^{1} \mathrm{H}$ NMR $\left(126 \mathrm{MHz}, 25{ }^{\circ} \mathrm{C}, \mathrm{CDCl}_{3}\right): \delta(\mathrm{ppm})=166.11,151.81,151.47,145.18,138.28,137.03,129.30$, 127.75, 123.53, 118.86, 95.42, 20.91. MS (ESI+): $m / z=480.17\left(\mathrm{M}+\mathrm{H}^{+}\right)$.

$\mathrm{Fe}(\mathrm{L2})_{2} \mathrm{OTf}_{2}$. To the solution of $96 \mathrm{mg}(0.2 \mathrm{mmol})$ of the compound $\mathrm{L} 2 \mathrm{in} 5 \mathrm{~mL}$ of acetonitrile, $35 \mathrm{mg}(0.1 \mathrm{mmol})$ of $\mathrm{Fe}(\mathrm{OTf})_{2}$ in $5 \mathrm{~mL}$ of acetonitrile was added in one portion. Reaction mixture immediately turned to orange-red colour. After stirring for $12 \mathrm{~h}$, volatiles were removes to produce a yellow solid in quantitative yield. Anal. Calcd for $\mathrm{C}_{56} \mathrm{H}_{42} \mathrm{~F}_{6} \mathrm{FeN}_{10} \mathrm{O}_{14} \mathrm{~S}_{2}(\%)$ : C, 51.23; $\mathrm{H}, 3.22 ; \mathrm{N}, 10.67$; $\mathrm{Fe}, 4.25$. Found (\%): C, C, 50.92; H, 3.54; N, 10.48; Fe, 4.30. ${ }^{1} \mathrm{H}$ NMR $\left(600 \mathrm{MHz}, 20^{\circ}, \mathrm{CD}_{3} \mathrm{CN}\right): \delta=59.65$ (br. s, 2H), 58.70 (br. s, 2H), 20.65 (br. s, 1H), 11.11 (br. s, 2H), 8.62 (br. s, $4 \mathrm{H}), 2.62$ (br. s, 6H), -6.33 (br. $\mathrm{s}, 4 \mathrm{H}) .{ }^{19} \mathrm{~F}$ NMR $\left(376 \mathrm{MHz}, 25^{\circ} \mathrm{C}, \mathrm{CD}_{3} \mathrm{CN}\right): \delta=-76.72(\mathrm{~s})$.

$\mathrm{Fe}(\mathrm{L2})_{2}\left(\mathrm{BF}_{4}\right)_{2}$. To the solution of $96 \mathrm{mg}(0.2 \mathrm{mmol})$ of the compound $\mathrm{L} 2 \mathrm{in} 5 \mathrm{~mL}$ of acetonitrile, $34 \mathrm{mg}(0.1 \mathrm{mmol})$ of $\mathrm{Fe}\left(\mathrm{BF}_{4}\right)_{2} \cdot 6 \mathrm{H}_{2} \mathrm{O}$ in $5 \mathrm{~mL}$ of acetonitrile was added in one portion. Reaction mixture immediately turned to orange-red colour. After stirring for $12 \mathrm{~h}$, volatiles were removed to produce a yellow solid in a quantitative yield. Anal. Calcd for $\mathrm{C}_{54} \mathrm{H}_{42} \mathrm{~B}_{2} \mathrm{~F}_{8} \mathrm{FeN}_{10} \mathrm{O}_{8}(\%)$ : C, 54.57; H, 3.56; N, 11.79; Fe, 4.70. Found (\%): C, 54.11; H, 3.86; N, 11.46; Fe, 4.90. ${ }^{1} \mathrm{H}$ NMR $\left(600 \mathrm{MHz}, 20{ }^{\circ} \mathrm{C}, \mathrm{CD}_{3} \mathrm{CN}\right)$ : $\delta=59.49$ (br. s, 2H), 58.47 (br. s, 2H), 20.56 (br. s, $1 \mathrm{H}$ ), 10.99 (br. s, 2H), 8.45 (br. s, $4 \mathrm{H}$ ), 2.59 (br. s, 6H), -6.82 (br. s, $4 \mathrm{H}) .{ }^{19} \mathrm{~F}$ NMR $\left(376 \mathrm{MHz}, 25^{\circ} \mathrm{C}, \mathrm{CD}_{3} \mathrm{CN}\right): \delta=-145.9$ (s). 
$\mathrm{Zn}(\mathrm{L1})_{2}\left(\mathrm{ClO}_{4}\right)_{2}$. To the suspension of $30 \mathrm{mg}(0.076 \mathrm{mmol})$ of the compound $\mathbf{L} 1 \mathrm{in} 2 \mathrm{~mL}$ of ethanol, $12 \mathrm{mg}(0.036 \mathrm{mmol})$ of $\mathrm{Zn}\left(\mathrm{ClO}_{4}\right)_{2} \cdot 4 \mathrm{H}_{2} \mathrm{O}$ was added in one portion. Reaction mixture was stirred for $2 \mathrm{~h}$ at r.t. and then refluxed for $1 \mathrm{~h}$, cooled to r.t., and evaporated to dryness. The solid product was washed with diethyl ether $(3 \times 7 \mathrm{~mL})$, dichloromethane $(2 \times 7 \mathrm{~mL})$ and extracted with acetonitrile $(2 \times 5 \mathrm{~mL})$. The extract was filtered and evaporated to dryness. Yield: $30 \mathrm{mg}(79 \%)$. Anal. Calcd for $\mathrm{C}_{46} \mathrm{H}_{34} \mathrm{~N}_{10} \mathrm{O}_{12} \mathrm{Cl}_{2} \mathrm{Zn}(\%)$ : C, 52.37; H, 3.22; N, 13.28. Found (\%): C, 52.16; H, 3.38; N, 13.07. ${ }^{1} \mathrm{H}$ NMR $\left(600 \mathrm{MHz}, 20^{\circ} \mathrm{C}\right.$, Acetonitrile-d3): $6.19\left(4 \mathrm{H}, \mathrm{s},{ }^{3} \mathrm{~J}_{\mathrm{HH}}=7.4 \mathrm{~Hz}, 4-\mathrm{Pyr}\right), 6.87\left(8 \mathrm{H}, \mathrm{d},{ }^{3} \mathrm{~J}_{\mathrm{HH}}=7.45 \mathrm{~Hz}, \mathrm{o}-\mathrm{Ph}\right)$, $6.95\left(8 \mathrm{H}, \mathrm{t},{ }^{3} \mathrm{~J}_{\mathrm{HH}}=7.4 \mathrm{~Hz}, \mathrm{~m}-\mathrm{Ph}\right), 7.05\left(4 \mathrm{H}, \mathrm{t},{ }^{3} \mathrm{~J}_{\mathrm{HH}}=7.16 \mathrm{~Hz}, \mathrm{p}-\mathrm{Ph}\right), 7.36\left(4 \mathrm{H}, \mathrm{d},{ }^{3} \mathrm{~J}_{\mathrm{HH}}=7.82 \mathrm{~Hz}, \mathrm{~m}-\mathrm{Py}\right)$, $7.79\left(2 \mathrm{H}, \mathrm{t},{ }^{3} \mathrm{~J}_{\mathrm{HH}}=7.82 \mathrm{~Hz}, \mathrm{p}-\mathrm{Py}\right), 9.41(4 \mathrm{H}, \mathrm{s}, \mathrm{OH}) .{ }^{13} \mathrm{C}\left\{{ }^{1} \mathrm{H}\right\} \mathrm{NMR}\left(600 \mathrm{MHz}, 20{ }^{\circ} \mathrm{C}\right.$, Acetonitrile-d $)$ : 86.95 (4-Pyr), 121.79 (m-Py), 126.23 (o-Ph), 129.56 (m-Ph), 130.57 (p-Ph), 135.55 (Ph-Py), 143.35 (p-Py), 146.45, 146.49 (5-Pr, Py-Pr), 155.66 (3-Pr).

Magnetic measurements. Magnetic susceptibility for the iron(II) complexes was measured in the temperature range 3-300 K with a Quantum Design PPMS-9 (Quantum Design Inc., San Diego, CA, USA) device under the $d c$ magnetic field of $1 \mathrm{kOe}$. Finely ground microcrystalline powders were immobilized in mineral oil matrix inside a polyethylene capsule. The data were corrected for the sample holder, the mineral oil and the diamagnetic contribution; the latter by using the Pascal constants [56]. Smoothing was performed by the Savitzky-Golay method with five points of window and polynomial order of two. The observed variable-temperature $d c$ magnetic susceptibility data were fitted in PHI software [33] using the spin Hamiltonian (Figure 1 and Figure S1):

$$
\hat{H}=D\left(\hat{S}_{z}^{2}-\frac{\hat{S}^{2}}{3}\right)+\beta H \cdot g_{i s o} \cdot \hat{S}
$$

X-ray crystallography. X-ray diffraction experiments of single crystals, which were grown by recrystallization of powder samples from dichloromethane (for $\mathrm{Fe}(\mathbf{L} 2)_{2} \mathrm{OTf}_{2}$ and $\left.\mathrm{Fe}(\mathbf{L} 2)_{2}\left(\mathrm{BF}_{4}\right)_{2}\right)$ or diffusion of diethyl ether to the solution in acetonitrile (for $\mathrm{Fe}(\mathbf{L} \mathbf{1})_{2} \mathrm{OTf} \mathrm{O}_{2}$ and $\left.\mathrm{Zn}(\mathbf{L} \mathbf{1})_{2}\left(\mathrm{ClO}_{4}\right)_{2}\right)$ on air, were carried out with a Bruker APEX2 DUO CCD diffractometer (for Fe( $\left.(\mathbf{L} 2)_{2}\left(\mathrm{BF}_{4}\right)_{2}\right)$ and with a Bruker APEX2 CCD diffractometer (for all others), using the graphite monochromated Mo-K $\alpha$ radiation $(\lambda=0.71073 \AA, \omega$-scans $)$ at $120 \mathrm{~K}$. The structures were solved by direct method and refined by the full-matrix least-squares against $F^{2}$ in anisotropic approximation for non-hydrogen atoms. Hydrogen atoms of $\mathrm{OH}$ groups (in $\mathrm{Fe}(\mathbf{L 1})_{2} \mathrm{OTf}_{2}$ and $\left.\mathrm{Zn}(\mathbf{L 1})_{2}\left(\mathrm{ClO}_{4}\right)_{2}\right)$ and those of solvate water molecules (in $\mathrm{Fe}(\mathbf{L} 2)_{2} \mathrm{OTf}_{2}$ and $\left.\mathrm{Zn}(\mathbf{L 1})_{2}\left(\mathrm{ClO}_{4}\right)_{2}\right)$, presumably absorbed from air, were located in difference Fourier synthesis. Positions of other hydrogen atoms were calculated, and they all were refined in the isotropic approximation in the riding model. Crystal data and structure refinement parameters for these complexes are given in Table S1. All calculations were performed using the SHELXTL software [57]. CCDC 1843948-1843951 contain the supplementary crystallographic data, which can be obtained free of charge via http:/ / www.ccdc.cam.ac.uk/conts/retrieving.html.

NMR spectroscopy. ${ }^{1} \mathrm{H} 1 \mathrm{D}$ and $2 \mathrm{D}$ NMR spectra were recorded from $\mathrm{CD}_{3} \mathrm{CN}$ solutions with a Bruker Avance 600 FT-spectrometer (600.22 and $150.96 \mathrm{MHz}$, respectively). The measurements were done using the residual signals of $\mathrm{CD}_{3} \mathrm{CN}\left({ }^{1} \mathrm{H} 1.94 \mathrm{ppm},{ }^{13} \mathrm{C} 118.26 \mathrm{ppm}\right)$. No change in chemical shifts was observed when using another solvent, such as methanol.

Evans method. Temperature dependence of magnetic susceptibility of the iron(II) complexes in acetonitrile solutions was evaluated by the Evans method $[25,26]$ in the temperature range $240-330 \mathrm{~K}$ (Figure 1 and Figure S1), using a Wilmad NMR tube with a coaxial insert. The inner (reference) tube was filled with acetonitrile- $\mathrm{d}_{3}$ with approximately $1 \%$ of $\mathrm{Me}_{4} \mathrm{Si}$, and the outer tube contained the solution of the complex $\left(\sim 5-10 \mathrm{mg} / \mathrm{cm}^{3}\right)$ in acetonitrile- $\mathrm{d}_{3}$ with the same concentration of $\mathrm{Me}_{4} \mathrm{Si}$. Molar magnetic susceptibility was calculated from the difference between the chemical shift of $\mathrm{Me}_{4} \mathrm{Si}$ in pure acetonitrile- $\mathrm{d}_{3}$ and its shift in a solution of the complex $(\Delta \delta$ in $\mathrm{Hz})$ in acetonitrile- $\mathrm{d}_{3}$ using the following equation:

$$
\chi_{M}=\frac{\Delta \delta M}{v_{0} S_{f} c}-\chi_{M}^{d i a}
$$


( $M-$ molar weight of the iron(II) complex; $v_{0}$-frequency of the spectrometer; $S_{f}$-shape factor of the magnet $(4 \pi / 3) ; c$ - concentration of the complex; $\chi_{M}{ }^{\text {dia }}$ - molar diamagnetic contribution to the paramagnetic susceptibility, calculated using the Pascal's constant [56]). The concentration $c$ was recalculated for each temperature in accordance with the density change of the solvent $\rho: c_{T}=m_{S} \rho / m_{s o l}$, where $m_{S}$ is the mass of the complex and $m_{\text {sol }}$ is the mass of the solution.

Analysis of paramagnetic chemical shifts. Paramagnetic shifts in ${ }^{1} \mathrm{H}$ NMR spectra for acetonitrile solutions of the iron(II) complexes were measured (as hundreds of ppm) as a difference between the observed chemical shifts and those for their diamagnetic analogue, the zinc(II) complex $\mathrm{Zn}(\mathbf{L 1})_{2}\left(\mathrm{ClO}_{4}\right)_{2}$ (for $\mathrm{Fe}(\mathbf{L} \mathbf{1})_{2} \mathrm{OTf} f_{2}$ ) or a free ligand $\mathbf{L} 2$ (for $\mathrm{Fe}(\mathbf{L} 2)_{2} \mathrm{OTf}_{2}$ and $\left.\mathrm{Fe}(\mathbf{L} 2)_{2}\left(\mathrm{BF}_{4}\right)_{2}\right)$. The theoretical chemical shifts for the iron(II) complexes were obtained as follows: $\delta_{o b s}=\delta_{d i a}+\delta_{C S}+\delta_{P C S}\left(\delta_{d i a}\right.$ is a diamagnetic contribution to the observed chemical shift (in ppm), which is taken as a chemical shift of the corresponding nucleus in the NMR spectra of a suitable diamagnetic analogue). Isotropic paramagnetic (contact) contribution $\delta_{C S}$, which arises from spin polarization conveyed through molecular orbitals, was evaluated through the following equation:

$$
\delta^{c s}=\frac{S(S+1) \mu_{B}}{3 k T g_{N} \mu_{N}} \cdot g_{i s o} \cdot A_{i s o}
$$

( $S$ - electron spin; $g_{N}$-nuclear g-factor; $\mu_{B}$-Borh magneton; $\mu_{N}$-nuclear magneton). The value of $g$-tensor and isotropic values of hyperfine interaction tensors $A_{\text {iso }}$ are taken from quantum chemical calculations [58], using optimized and X-ray geometries (with the positions of hydrogen atoms optimized as described below) of the iron(II) complexes. The pseudocontact contribution $\delta_{P C S}$, which arises from dipolar coupling between magnetic moments of a nucleus and of an unpaired electron $[35,59,60]$, was estimated by fitting the observed chemical shifts with the following equation:

$$
\delta_{i}^{C a l}=\frac{1}{12 \pi r_{i}{ }^{3}} \Delta \chi_{a x}\left(3 \cos ^{2} \theta_{i}-1\right)+\delta_{i}^{C S}+\delta_{i}^{d i a}
$$

$\left(\theta_{i}\right.$ and $r_{i}$-polar coordinates of the nuclei in the coordinate frame of the magnetic susceptibility tensor $\mathrm{X} ; \Delta \mathrm{x}_{a x}$-axial anisotropy of $\left.\mathrm{X}\right)$.

Quantum chemistry. All quantum chemical calculations were done using the ORCA package, v. 4.0 [61]. Geometry optimization of the ligands was performed with a PBE0 functional [62] and a basis set def2-TZVP [63]. For the metal complexes, X-ray diffraction geometries were used as a starting point for geometry optimization with the hybrid PBE0 functional (providing simultaneously good results for the energy difference between HS and LS states in octahedral Fe(II) complexes [64] and for hydrogen spin densities [65] used in calculating chemical shifts in NMR spectra of paramagnetic compounds [29]), the scalar relativistic zero-order regular approximation (ZORA) [66], Grimme's DFT-D3 dispersion correction [67] and the scalar relativistically recontracted (SARC) [68] version of the def2-TZVP basis set [63]. Extra tight thresholds for forces and displacements were used. The solvation effects were included using the Conductor-like Polarizable Continuum Model, as implemented in ORCA 4.0, with acetonitrile as a solvent. The resulting geometries of $\left[\mathrm{Fe}(\mathbf{L} \mathbf{1})_{2}\right]^{2+}$ and $\left[\mathrm{Fe}(\mathbf{L} 2)_{2}\right]^{2+}$ in the HS state were used to compute g-tensor and isotropic values of hyperfine interaction tensors $A_{\text {iso }}$ [58]. A model complex $\left[\mathrm{Fe}\left(\mathrm{Ph}_{2}-3-\mathrm{bpp}\right)_{2}\right]^{2+}$ was calculated in a similar way in its LS and HS states.

\section{Conclusions}

A combined study of four complexes with the 1-phenylsubstituted 3-bpp ligands that have different other substituents (with distinct steric and electronic properties and H-bonding ability), counterions, lattice solvents and even the metal ions (bistable iron(II) and diamagnetic zinc(II)) by magnetochemistry, X-ray diffraction and multi-temperature NMR spectroscopy provided an experimental evidence for the intramolecular origin of their HS locking (the HS state being thermodynamically more stable than the LS state) and the distorted molecular geometry, both found in 
iron(II) complexes of similar 1-bpp [34], 1,3-bpp [17] and terpy [51,52] ligands. It was attributed to the pendant phenyl groups that act through an energetically unfavourable rotation to avoid steric clashes with the second ligand [17] and, apparently, intramolecular 'parallel displaced' stacking interactions; the latter are shared by complexes with different tri-dentate ligands and aromatic substituents, such as phenyl [34], p-tolyl [51], metoxyphenyl [53] and pyridyl [54]. They are therefore guaranteed to yield the HS iron(II) complexes, which in the case of 1-unsubstituted 3-bpp is hindered by a dramatic influence of the environment on the spin state [69] owing to its NH groups (so that there is no clear correlation with the electromeric characteristics of other substituents) [15].

Even if found in one spin state, a thorough characterization of iron(II) complexes with new derivatives of 3-bpp and the like (including heteroleptic complexes [55]), especially in solutions, is a key to more accurate magneto-structural correlations. Together with a possibility for their high-throughput screening by variable-temperature NMR spectroscopy to identify a spin transition by paramagnetic shifts and even quantify it by the proposed approach (applicable to compounds obtained in situ without their isolation or purification, in contrast to the popular Evans method) [29], it paves the way to a truly 'molecular' design [15] of spin transition compounds for many future applications [3].

Supplementary Materials: The following are available online at http://www.mdpi.com/2312-7481/4/4/ 46/s1, Table S1: Crystal data and structure refinement parameters for the studied complexes, Figure S1: Variable-temperature magnetic susceptibility data for microcrystalline samples of $\mathrm{Fe}(\mathbf{L} 2)_{2} \mathrm{OTf}_{2}$ and Fe$(\mathbf{L} 2)_{2}\left(\mathrm{BF}_{4}\right)_{2}$ according to $d c$-magnetometry and for their acetonitrile- $\mathrm{d}_{3}$ solutions according to the Evans method, Figure S2: ${ }^{1} \mathrm{H}$ chemical shifts for an acetonitrile- $\mathrm{d}_{3}$ solution of $\mathrm{Fe}(\mathbf{L} 2)_{2} \mathrm{OTf}_{2}$ and $\mathrm{Fe}(\mathbf{L} 2)_{2}\left(\mathrm{BF}_{4}\right)_{2}$ plotted versus $1 / T$, Figures S3 and S4: Correlation plot of experimental vs. theoretical ${ }^{1} \mathrm{H}$ chemical shifts for $\mathrm{Fe}(\mathbf{L} 2)_{2} \mathrm{OTf}_{2}$ and Fe( $(\mathbf{L} 2)_{2}\left(\mathrm{BF}_{4}\right)_{2}$, Figures S5 and S6: Packing of $\left[\mathrm{ML}_{2}\right]^{2+}$ cations in $\mathrm{Fe}(\mathbf{L 1})_{2} \mathrm{OTf}_{2}, \mathrm{Zn}(\mathbf{L 1})_{2}\left(\mathrm{ClO}_{4}\right)_{2}, \mathrm{Fe}(\mathbf{L 2})_{2} \mathrm{OTf}_{2}$ and Fe$(\mathbf{L} 2)_{2}\left(\mathrm{BF}_{4}\right)_{2}$ Figure S7: Organic compounds with a phenyl-pyrazol-1-yl or phenyl-pyrazol-3-yl fragment distributed over the angle between the two planes, Figure S8: ${ }^{1} \mathrm{H}$ NMR spectra of the ligand $\mathbf{L 1}$ and the complex $\left.\mathrm{Zn}(\mathbf{L 1})_{2}(\mathrm{ClO})_{4}\right)_{2}$, Figure S9: Differences in ${ }^{1} \mathrm{H}$ chemical shifts between the complex $\mathrm{Zn}(\mathbf{L 1})_{2}\left(\mathrm{ClO}_{4}\right)_{2}$ and the ligand L1, Figure S10: ROESY NMR data for $\mathrm{Zn}(\mathbf{L} 1)_{2}\left(\mathrm{ClO}_{4}\right)_{2}$, Figure S11: General view of the HS complexes $\left[\mathrm{Fe}(\mathrm{L})_{2}\right]^{2+}$ of terpy and bpp with phenyl groups (and similar) from CSD showing 'parallel-displaced' intramolecular stacking interactions, Figure S12: ${ }^{1} \mathrm{H}$ NMR spectra recorded after adding equimolar quantities of $\mathbf{L 1}$, terpy and $\mathrm{FeCl}_{2}$ in methanol-d4.

Author Contributions: Conceptualization, Y.N. and V.N.; methodology, Y.N., A.P. (Alexander Polezhaev) and A.P. (Alexander Pavlov); validation, Y.N., A.P. (Alexander Polezhaev), A.P. (Alexander Pavlov), S.S., N.E. and T.A.; formal analysis, Y.N., A.P. (Alexander Pavlov) and D.A.; investigation, Y.N., A.P. (Alexander Pavlov) and D.A.; writing-original draft preparation, Y.N., A.P. (Alexander Polezhaev) and A.P. (Alexander Pavlov); writing-review and editing, Y.N. and V.N.; supervision, Y.N. and V.N.; project administration, Y.N. and V.N.; funding acquisition, Y.N.

Funding: This research was funded by Russian Science Foundation, grant number 17-13-01456.

Acknowledgments: The authors gratefully acknowledge support of the Center for molecular composition studies of INEOS RAS in collecting X-ray diffraction and NMR data.

Conflicts of Interest: The authors declare no conflicts of interest.

\section{References}

1. Halcrow, M.A. Spin-Crossover Materials: Properties and Applications; John Wiley \& Sons, Ltd.: Hoboken, NJ, USA, 2013.

2. Gutlich, P.; Gaspar, A.B.; Garcia, Y. Spin state switching in iron coordination compounds. Beilstein J. Org. Chem. 2013, 9, 342. [CrossRef] [PubMed]

3. Hayami, S.; Holmes, S.M.; Halcrow, M.A. Spin-state switches in molecular materials chemistry. J. Mat. Chem. C 2015, 3, 7775-7778. [CrossRef]

4. Molnar, G.; Rat, S.; Salmon, L.; Nicolazzi, W.; Bousseksou, A. Spin Crossover Nanomaterials: From Fundamental Concepts to Devices. Adv. Mater. 2017, 30, 1703862. [CrossRef] [PubMed]

5. Senthil Kumar, K.; Ruben, M. Emerging trends in spin crossover (SCO) based functional materials and devices. Coord. Chem. Rev. 2017, 346, 176-205. [CrossRef]

6. Halcrow, M.A. Structure: Function relationships in molecular spin-crossover complexes. Chem. Soc. Rev. 2011, 40, 4119-4142. [CrossRef] [PubMed] 
7. Halcrow, M.A. The synthesis and coordination chemistry of 2,6-bis(pyrazolyl)pyridines and related ligands-Versatile terpyridine analogues. Coord. Chem. Rev. 2005, 249, 2880-2908. [CrossRef]

8. Halcrow, M.A. Iron(II) complexes of 2,6-di(pyrazol-1-yl)pyridines-A versatile system for spin-crossover research. Coord. Chem. Rev. 2009, 253, 2493-2514. [CrossRef]

9. Kershaw Cook, L.J.; Kulmaczewski, R.; Mohammed, R.; Dudley, S.; Barrett, S.A.; Little, M.A.; Deeth, R.; Halcrow, M.A. A Unified Treatment of the Relationship between Ligand Substituents and Spin State in a Family of Iron(II) Complexes. Angew. Chem. Int. Ed. 2016, 55, 4327-4331. [CrossRef] [PubMed]

10. Alvarez, S. Distortion Pathways of Transition Metal Coordination Polyhedra Induced by Chelating Topology. Chem. Rev. 2015, 115, 13447-13483. [CrossRef] [PubMed]

11. Canton, S.E.; Zhang, X.; Lawson Daku, M.L.; Liu, Y.; Zhang, J.; Alvarez, S. Mapping the Ultrafast Changes of Continuous Shape Measures in Photoexcited Spin Crossover Complexes without Long-Range Order. J. Phys. Chem. C 2015, 119, 3322-3330. [CrossRef]

12. Kershaw Cook, L.; Mohammed, R.; Sherborne, G.; Roberts, T.D.; Alvarez, S.; Halcrow, M.A. Spin state behavior of iron(II)/dipyrazolylpyridine complexes. New insights from crystallographic and solution measurements. Coord. Chem. Rev. 2015, 289-290, 2-12. [CrossRef]

13. Kershaw Cook, L.J.; Thorp-Greenwood, F.L.; Comyn, T.P.; Cespedes, O.; Chastanet, G.; Halcrow, M.A. Unexpected Spin-Crossover and a Low-Pressure Phase Change in an Iron(II)/Dipyrazolylpyridine Complex Exhibiting a High-Spin Jahn-Teller Distortion. Inorg. Chem. 2015, 54, 6319-6330. [CrossRef] [PubMed]

14. Craig, G.A.; Costa, J.S.; Roubeau, O.; Teat, S.J.; Aromi, G. Local Coordination Geometry and Spin State in Novel Fe ${ }^{I I}$ Complexes with 2,6-Bis(pyrazol-3-yl)pyridine?Type Ligands as Controlled by Packing Forces: Structural Correlations. Chem. Eur. J. 2012, 18, 11703-11715. [CrossRef] [PubMed]

15. Halcrow, M.A. The Effect of Ligand Design on Metal Ion Spin State-Lessons from Spin Crossover Complexes. Crystals 2016, 6, 58. [CrossRef]

16. Roberts, T.D.; Little, M.A.; Kershaw Cook, L.J.; Barrett, S.A.; Tuna, F.; Halcrow, M.A. Iron(II) complexes of 2,6-di(1-alkylpyrazol-3-yl)pyridine derivatives-The influence of distal substituents on the spin state of the iron centre. Polyhedron 2013, 64, 4-12. [CrossRef]

17. Bartual-Murgui, C.; Vela, S.; Roubeau, O.; Aromi, G. Designed intramolecular blocking of the spin crossover of an Fe(II) complex. Dalton Trans. 2016, 45, 14058-14062. [CrossRef] [PubMed]

18. Alvarez, S. A cartography of the van der Waals territories. Dalton Trans. 2013, 42, 8617-8636. [CrossRef] [PubMed]

19. Holland, J.M.; Barrett, S.A.; Kilner, C.A.; Halcrow, M.A. Control of the spin state of Fe(II) 2,6-di(pyrazol1-yl)pyridine complexes by distal ligand substitution. Inorg. Chem. Commun. 2002, 5, 328-332. [CrossRef]

20. Petzold, H.; Djomgoue, P.; Horner, G.; Lochenie, C.; Weber, B.; Ruffer, T. Bis-meridional Fe ${ }^{2+}$ spincrossover complexes of phenyl and pyridyl substituted 2-(pyridin-2-yl)-1,10-phenanthrolines. Dalton Trans. 2018, 47, 491-506. [CrossRef] [PubMed]

21. Elhaik, J.; Evans, D.J.; Kilner, C.A.; Halcrow, M.A. A structural, magnetic and Mossbauer spectroscopic study of an unusual angular Jahn-Teller distortion in a series of high-spin iron(II) complexes. Dalton Trans. 2005, 1693-1700. [CrossRef] [PubMed]

22. Roberts, T.D.; Little, M.A.; Kershaw Cook, L.J.; Halcrow, M.A. Iron(II) complexes of 2,6-di(1H-pyrazol3-yl)-pyridine derivatives with hydrogen bonding and sterically bulky substituents. Dalton Trans. 2014, 43, 7577-7588. [CrossRef] [PubMed]

23. Polezhaev, A.V.; Chen, C.-H.; Kinne, A.S.; Cabelof, A.C.; Lord, R.L.; Caulton, K.G. Ligand Design toward Multifunctional Substrate Reductive Transformations. Inorg. Chem. 2017, 56, 9505-9514. [CrossRef] [PubMed]

24. Kimura, A.; Ishida, T. Spin-Crossover Temperature Predictable from DFT Calculation for Iron(II) Complexes with 4-Substituted Pybox and Related Heteroaromatic Ligands. ACS Omega 2018, 3, 6737-6747. [CrossRef]

25. Evans, D.F. The determination of the paramagnetic susceptibility of substances in solution by nuclear magnetic resonance. J. Chem. Soc. 1959, 2003-2005. [CrossRef]

26. Piguet, C. Paramagnetic Susceptibility by NMR: The “Solvent Correction" Removed for Large Paramagnetic Molecules. J. Chem. Educ. 1997, 74, 815. [CrossRef]

27. Petzold, H.; Djomgoue, P.; Horner, G.; Speck, J.M.; Ruffer, T.; Schaarschmidt, D. 1H NMR spectroscopic elucidation in solution of the kinetics and thermodynamics of spin crossover for an exceptionally robust $\mathrm{Fe}^{2+}$ complex. Dalton Trans. 2016, 45, 13798-13809. [CrossRef] [PubMed] 
28. Petzold, H.; Djomgoue, P.; Horner, G.; Heider, S.; Lochenie, C.; Weber, B.; Ruffer, T.; Schaarschmidt, D. Spin state variability in $\mathrm{Fe}^{2+}$ complexes of substituted (2-(pyridin-2-yl)-1,10-phenanthroline) ligands as versatile terpyridine analogues. Dalton Trans. 2017, 46, 6218-6229. [CrossRef] [PubMed]

29. Pavlov, A.A.; Denisov, G.L.; Kiskin, M.A.; Nelyubina, Y.V.; Novikov, V.V. Probing Spin Crossover in a Solution by Paramagnetic NMR Spectroscopy. Inorg. Chem. 2018, 56, 14759-14762. [CrossRef] [PubMed]

30. Halcrow, M.A.; Kilner, C.A.; Thornton-Pett, M. Bis\{2,6-bis[3-(2,4,6-trimethylphenyl)-pyrazol-1-ylkN2]pyridine-jN\}zinc(II) diperchlorate bis(nitromethane) solvate. Acta Cryst. C 2000, 56, 1425-1426. [CrossRef]

31. Solanki, N.K.; Leech, M.A.; McInnes, E.J.L.; Mabbs, F.E.; Howard, J.A.K.; Kilner, C.A.; Rawson, J.M.; Halcrow, M.A. A crystallographic and EPR study of the fluxional Cu(II) ion in [CuL2][BF4]2(L = 2,6-dipyrazol1-ylpyridine). J. Chem. Soc.-Dalton Trans. 2002, 1295-1301. [CrossRef]

32. Balde, C.; Desplanches, C.; Le Gac, F.; Guionneau, P.; Letard, J.-F. The role of iron(II) dilution in the magnetic and photomagnetic properties of the series $\left[\mathrm{Fe}_{\mathrm{x}} \mathrm{Zn}_{1-\mathrm{x}}(\mathrm{bpp})_{2}\right](\mathrm{NCSe})_{2}$. Dalton Trans. 2014, 43, 7820-7829. [CrossRef] [PubMed]

33. Chilton, N.F.; Anderson, R.P.; Turner, L.D.; Soncini, A.; Murray, K.S. Phi: A Powerful New Program for the Analysis of Anisotropic Monomeric and Exchange-Coupled Polynuclear D- and F-Block Complexes. J. Comput. Chem. 2013, 34, 1164-1175. [CrossRef] [PubMed]

34. Elhaik, J.; Kilner, C.A.; Halcrow, M.A. Structural diversity in iron(II) complexes of 2,6-di(pyrazol-1yl)pyridine and 2,6-di(3-methylpyrazol-1-yl)pyridine. Dalton Trans. 2006, 823-830. [CrossRef] [PubMed]

35. Bertini, I.; Luchinat, C.; Parigi, G.; Ravera, E. Solution NMR of Paramagnetic Molecules, 2nd ed.; Applications to Metallobiomolecules and Models; Elsevier: New York, NY USA, 2015.

36. Pavlov, A.A.; Nelyubina, Y.V.; Kats, S.V.; Penkova, L.V.; Efimov, N.N.; Dmitrienko, A.O.; Vologzhanina, A.V.; Belov, A.S.; Voloshin, Y.Z.; Novikov, V.V. Polymorphism in a Cobalt-Based Single-Ion Magnet Tuning Its Barrier to Magnetization Relaxation. J. Phys. Chem. Lett. 2016, 7, 4111-4116. [CrossRef] [PubMed]

37. Novikov, V.V.; Pavlov, A.A.; Belov, A.S.; Vologzhanina, A.V.; Savitsky, A.; Voloshin, Y.Z. Transition Ion Strikes Back: Large Magnetic Susceptibility Anisotropy in Cobalt(II) Clathrochelates. J. Phys. Chem. Lett. 2016, 5, 3799-3803. [CrossRef] [PubMed]

38. Pavlov, A.A.; Savkina, S.A.; Belov, A.S.; Nelyubina, Y.V.; Efimov, N.N.; Voloshin, Y.Z.; Novikov, V.V. Trigonal Prismatic Tris-pyridineoximate Transition Metal Complexes: A Cobalt(II) Compound with High Magnetic Anisotropy. Inorg. Chem. 2017, 56, 6943-6951. [CrossRef] [PubMed]

39. Bertini, I.; Luchinat, C.; Parigi, G.; Pierattelli, R. NMR Spectroscopy of Paramagnetic Metalloproteins. ChemBioChem 2005, 6, 1536-1549. [CrossRef] [PubMed]

40. Pritchard, R.; Kilner, C.A.; Halcrow, M.A. Iron(II) complexes with a terpyridine embrace packing motif show remarkably consistent cooperative spin-transitions. Chem. Commun. 2007, 577-579. [CrossRef] [PubMed]

41. Gimenez-Lopez, M.C.; Clemente-Leon, M.; Gimenez-Saiz, C. Unravelling the spin-state of solvated $\left[\mathrm{Fe}(\mathrm{bpp})_{2}\right]^{2+}$ spin-crossover complexes: Structure-function relationship. Dalton Trans. 2018, 47, 10453-10462. [CrossRef] [PubMed]

42. Ashley, D.C.; Jakubikova, E. Ray-Dutt and Bailar Twists in Fe(II)-Tris(2,2'-bipyridine): Spin States, Sterics, and Fe-N Bond Strengths. Inorg. Chem. 2018, 57, 5585-5596. [CrossRef] [PubMed]

43. Alvarez, S. Relationships between Temperature, Magnetic Moment, and Continuous Symmetry Measures in Spin Crossover Complexes. J. Am. Chem. Soc. 2003, 125, 6795-6802. [CrossRef] [PubMed]

44. Guan, Q.-L.; Liu, Z.; Wei, W.-J.; Xing, Y.-H.; Liu, J.; Zhang, R.; Hou, Y.-N.; Wang, X.; Bai, F.-Y. Synthesis, structure, spectroscopy of four novel supramolecular complexes and cytotoxicity study by application of multiple parallel perfused microbioreactors. New J. Chem. 2014, 38, 3258-3268. [CrossRef]

45. Bondi, A. van der Waals Volumes and Radii of Metals in Covalent Compounds. J. Phys. Chem. 1966, 70, 3006-3007. [CrossRef]

46. Batsanov, S.S. Van der Waals Radii of Elements. Inorg. Mater. 2001, 37, 871-885. [CrossRef]

47. Money, V.A.; Carbonera, C.; Elhaik, J.; Halcrow, M.A.; Howard, J.A.K.; Letard, J.-F. Interplay between Kinetically Slow Thermal Spin-Crossover and Metastable High-Spin State Relaxation in an Iron(II) Complex with Similar T1/2 and T(LIESST). Chem. Eur. J. 2007, 13, 5503-5514. [CrossRef] [PubMed]

48. Wheeler, S.E. Understanding Substituent Effects in Noncovalent Interactions Involving Aromatic Rings. Acc. Chem. Res. 2013, 46, 1029-1038. [CrossRef] [PubMed] 
49. Hohenstein, E.G.; Sherrill, C.D. Effects of Heteroatoms on Aromatic Interactions: Benzene-Pyridine and Pyridine Dimer. J. Phys. Chem. A 2009, 113, 878-886. [CrossRef] [PubMed]

50. Wang, L.; Pan, H.-R.; Yang, Q.; Fu, H.-Y.; Chen, H.; Li, R.-X. A family of novel cationic ruthenium pincer complexes: Synthesis, characterization and catalytic activity in the transfer hydrogenation of ketones. Inorg. Chem. Comm. 2011, 14, 1422-1427. [CrossRef]

51. Pelascini, F.; Wesolek, M.; Peruch, F.; Cian, A.D.; Kyritsakas, N.; Lutz, P.J.; Kress, J. Iron complexes of terdentate nitrogen ligands: Formation and X-ray structure of three new dicationic complexes. Polyhedron 2004, 23, 3193-3199. [CrossRef]

52. Constable, E.C.; Baum, G.; Bill, E.; Dyson, R.; van Eldik, R.; Fenske, D.; Kaderli, S.; Morris, D.; Neubrand, A.; Neuburger, M.; et al. Control of Iron(II) Spin States in 2,2': $6^{\prime}, 2^{\prime \prime}$-Terpyridine Complexes through Ligand Substitution. Chem. Eur. J. 1999, 5, 498-508. [CrossRef]

53. Brauchli, S.Y.; Constable, E.C.; Harris, K.; Haussinger, D.; Housecroft, C.E.; Rosel, P.J.; Zampese, J.A. Towards catenanes using pi-stacking interactions and their influence on the spin-state of a bis $\left(2,2^{\prime}: 6^{\prime}, 2^{\prime \prime}-\right.$ terpyridine)iron(II) domain. Dalton Trans. 2010, 39, 10739-10748. [CrossRef] [PubMed]

54. Dell'Amico, D.B.; Calderazzo, F.; Englert, U.; Labella, L.; Marchetti, F. The first crystallographically established bis-qtpy (qtpy $=2,2^{\prime} 6^{\prime}, 2^{\prime \prime} 6^{\prime \prime}, 2^{\prime \prime \prime}$-quaterpyridine) metal complex. J. Chem. Soc.-Dalton Trans. 2001, 357-358. [CrossRef]

55. Barrios, L.A.; Bartual-Murgui, C.; Peyrecave-Lleixa, E.; Le Guennic, B.; Teat, S.J.; Roubeau, O.; Aromi, G. Homoleptic versus Heteroleptic Formation of Mononuclear Fe(II) Complexes with Tris-Imine Ligands. Inorg. Chem. 2016, 55, 4110-4116. [CrossRef] [PubMed]

56. Bain, G.A.; Berry, J.F. Diamagnetic Corrections and Pascal's Constants. J. Chem. Educ. 2008, 85, 532. [CrossRef]

57. Sheldrick, G.M. A short history of SHELX. Acta Cryst. A 2008, 64, 112-122. [CrossRef] [PubMed]

58. Kaupp, M.; Michael, B.; Malkin, V.G. Calculation of NMR and EPR Parameters: Theory and Applications; John Wiley \& Sons: Hoboken, NJ, USA, 2006.

59. Bertini, I.; Luchinat, C. NMR of Paramagnetic Substances. Coord. Chem. Rev. 1996, 150, 1-296.

60. Bertini, I.; Luchinat, C.; Parigi, G. Magnetic susceptibility in paramagnetic NMR. Prog. Nucl. Magn. Reson. Spectrosc. 2002, 40, 249-273. [CrossRef]

61. Neese, F. The ORCA program system. Wiley Interdiscip. Rev. Comput. Mol. Sci. 2012, 2, 73-78. [CrossRef]

62. Adamo, C.; Barone, V. Toward reliable density functional methods without adjustable parameters: The PBE0 model. J. Chem. Phys. 1999, 110, 6158. [CrossRef]

63. Weigend, F.; Ahlrichs, R. Balanced basis sets of split valence, triple zeta valence and quadruple zeta valence quality for H to Rn: Design and assessment of accuracy. Phys. Chem. Chem. Phys. 2005, 7, 3297-3305. [CrossRef] [PubMed]

64. Song, S.; Kim, M.-C.; Sim, E.; Benali, A.; Heinonen, O.; Burke, K. Benchmarks and Reliable DFT Results for Spin Gaps of Small Ligand Fe(II) Complexes. J. Chem. Theory Comput. 2018, 14, 2304-2311. [CrossRef] [PubMed]

65. Kaupp, M.; Buhl, M.; Malkin, V.G. Calculation of NMR and EPR Parameters: Theory and Applications; WILEY-VCH Verlag GmbH \& Co.: Weinheim, Germany, 2004.

66. van Wullen, C. Molecular density functional calculations in the regular relativistic approximation: Method, application to coinage metal diatomics, hydrides, fluorides and chlorides, and comparison with first-order relativistic calculations. J. Chem. Phys. 1998, 109, 392-399. [CrossRef]

67. Grimme, S.; Antony, J.; Ehrlich, S.; Krieg, H. A consistent and accurate ab initio parametrization of density functional dispersion correction (DFT-D) for the 94 elements H-Pu. J. Chem. Phys. 2010, 132, 154104. [CrossRef] [PubMed]

68. Pantazis, D.A.; Chen, X.-Y.; Landis, C.R.; Neese, F. All-electron scalar relativistic basis sets for third-row transition metal atoms. J. Chem. Theory Comput. 2008, 4, 908-919. [CrossRef] [PubMed]

69. Barrett, S.A.; Halcrow, M.A. Anion-dependent spin crossover in solution for an iron(II) complex of a 1H-pyrazolyl ligand. RSC Adv. 2014, 4, 11240-11243. [CrossRef]

(C) 2018 by the authors. Licensee MDPI, Basel, Switzerland. This article is an open access article distributed under the terms and conditions of the Creative Commons Attribution (CC BY) license (http:// creativecommons.org/licenses/by/4.0/). 